PERSPECTIVE

\title{
A chronic grey matter penumbra, lateral microvascular intussusception and venous peduncular avulsion underlie diabetic vitreous haemorrhage
}

\section{David McLeod}

Br J Ophthalmol 2007;91:677-689. doi: 10.1136/bjo.2006.109199

The landmark publications that gave such impetus to our understanding of proliferative diabetic retinopathy are reviewed in the light of more recent reports. Briefly, confluence of small areas of capillary closure in the midperipheral and peripheral retina results in arteriovenous shunting and abnormal oxygen partial pressure gradients. These gradients embrace a chronic ischaemic penumbra that stimulates neuroglial secretion of angiogenic growth factors and upregulation of their receptors in the retinal venous endothelium and adventitia. The blood shunting produces biomechanical stresses within the veins and induces microvascular intussusception near arteriovenous crossings, giving way to neovascular outgrowths and/or segmental venous lesions (such as omega loops and coils) that penetrate the inner limiting lamina. The lamellar collagenous matrix of the vitreous cortex is then exploited for integrin-dependent rete expansion along chemotactic gradients. During posterior vitreous detachment, haemorrhaging takes place from the arterialised veins as venous neovascular peduncles are avulsed.

Correspondence to: ProfessorEmeritusDMcLeod, Academic Department of Ophthalmology, Manchester Royal Eye Hospital, Oxford Road, Manchester M13 9WH, UK; david.mcleod@ cmmc.nhs.uk

Accepted 12 December 2006
$\mathrm{T}$ he growth of preretinal new vessels (PRNVs) and optic disc new vessels (ODNVs) in sents an aberrant angiogenic response to ischaemia of the inner retina (fig 1 ). ${ }^{1}$ This essay revisits the pivotal publications that advanced or substantiated the key hypotheses surrounding PDR.

\section{VENOUS LOOPS, RETE MIRABILE AND MICROVASCULAR INTUSSUSCEPTION}

In 1946, Arthur Ballantyne ${ }^{2}$ provided one of the first clinicopathological descriptions of PDR. He observed endothelial cell proliferation throughout the retinal venous system together with hyaline thickening (phlebosclerosis) of the walls of those beaded veins from which new blood vessels and segmental venous abnormalities originated. Focal erosions of the internal limiting membrane then permitted the emergence of discrete neovascular projections into the vitreous cavity, whereas much wider dehiscences accommodated venous coils, knots and omega loops, as shown by serial retinal sectioning. ${ }^{2}{ }^{3}$ These segmental lesions were subsequently dubbed "benign forms of retinitis proliferans", and emphasise the scope of Ballentyne's vasoproliferative concept. ${ }^{4}$ proliferative diabetic retinopathy (PDR) repre-
Although early PRNVs appeared "naked" on fundoscopy, histopathological examination of these outgrowths disclosed a prominent interstitial component which Ballantyne attributed to "metaplasia of the tissue of the vein wall". This component was evident well ahead of the wave of fibroblast proliferation and collagen synthesis marking the second, fibrotic clinical phase of PDR. ${ }^{2-8}$ Meanwhile, he applied the term rete mirabile to the network that is formed when a venous outgrowth divides into a substantial number of branches that ultimately reunite into a single stem. These neovascular expansions, comprising vessels of capillary structure but of far greater diameter, frequently terminated in a brush-like arrangement of loops.

The fact that PRNVs sometimes arise from segmental venous lesions, and the capability of both pathologies to dissolve the inner limiting lamina (ILL), suggest that similar pathogenetic mechanisms are operating. ${ }^{3-5} 9$ Each is compatible with intussusception, a recently expounded concept of microvascular growth, branching and remodelling based on internal division of the parent vessel ("growth from within"). Thus, rearrangement of endothelial cells and intrusion of a pillar of interstitial tissue comprising fibroblasts, myofibroblasts and pericytes leads to partitioning of a vein's lumen. Alternatively, fusion of luminal evaginations on either side of a partial tissue septum establishes a patent loop within the vein wall (fig 2 A,B)..$^{10-13}$ Elongation of such loops and generation of new vascular elements extend the process, while collagen deposition provides mechanical stability. All channels remain perfused unless thrombosed or closed by cellular invasion during remodelling or regression.

A novel hypothesis encompassing Ballantyne's observations is therefore proposed. Predominantly lengthwise progression of partitioning along the course of the parent vein gives rise to loops, coils and parallel channels (venous reduplication),

Abbreviations: CRA, central retinal artery; CRV, central retinal vein; $E C M$, extracellular matrix; $E R M$, epiretinal membrane; FFA, fundus fluorescein angiography; GMP, grey matter penumbra; ILL, inner limiting lamina; MVI, microvascular intussusception; ODNV, optic disc new vessel; PDR, proliferative diabetic retinopathy; PHM, posterior hyaloid membrane; PIGF, placental growth factor; PRNV, preretinal new vessel; RAV, radiating anastomosing vessel; VEGF, vascular endothelial growth factor; VEGFR, vascular endothelial growth factor receptor; VNP, venous neovascular peduncle 

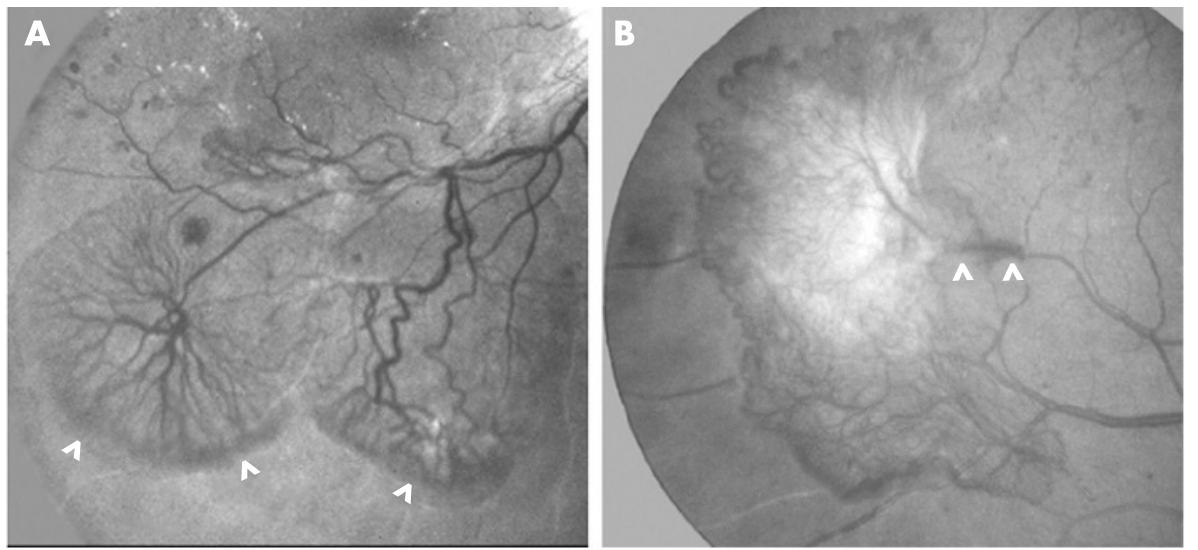

Figure 1 Preretinal and prepapillary new vessels. (A) Two rete expansions directed inferotemporally towards the ischaemic periphery; truncated cartwheel configuration of preretinal new vessels and brushes of delicate terminal loops (arrowheads). (B) Fibrovascular epiretinal membrane directed temporally towards the ischaemic periphery; marginal vessels; elongated peduncle (between arrowheads) arising from arteriovenous crossing. (C) Multiple feeder vessels from the optic disc serve rete expansion within preretinal vitreous cortex; brushes of terminal loops. (D) Diaphanous rete of peripapillary optic disc new vessels with aneurysmal dilatations at the limit of rete expansion.
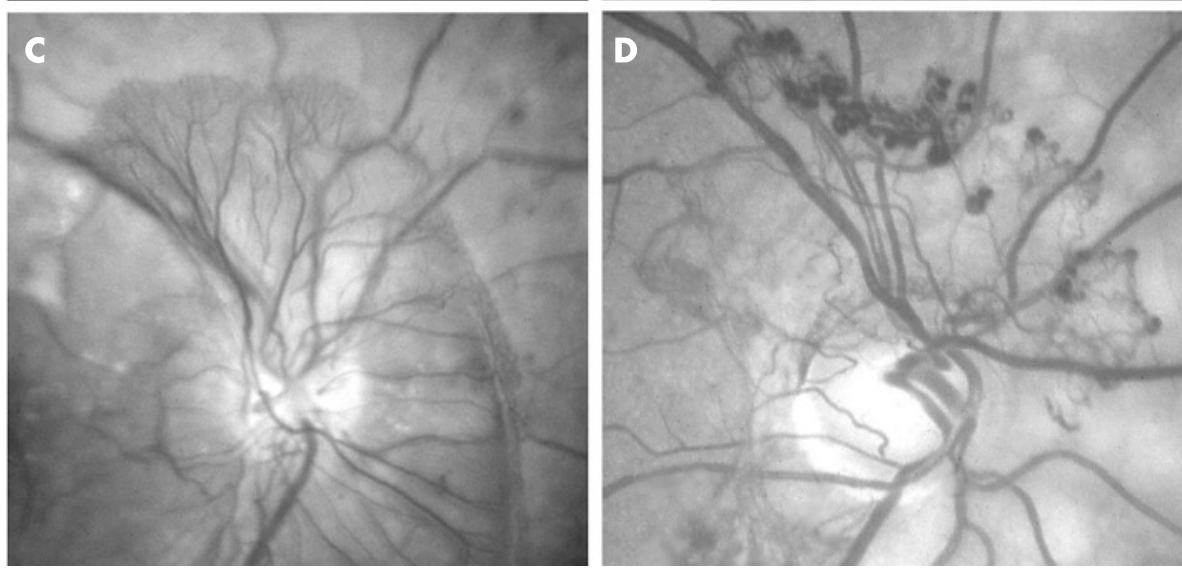

whereas arborisation directed laterally away from the trunk vessel results in formation of a rete mirabile (fig 2). Lateral microvascular intussusception (MVI) is more energy efficient than "sprouting", the classical mode of angiogenesis, since this requires endothelial cells to proliferate and form blind-ending tubes that must stabilise and fuse with each other to allow rete perfusion. ${ }^{14}{ }^{15}$ A blood-filled lumen extending to the distal limit of the neovascular networks, and thus implicating MVI, has been demonstrated in serial reconstructions of excised diabetic preretinal tissue. $^{16}$

MVI readily explains how venous neovascular peduncles (VNPs) are generated. Each incorporates an afferent and efferent stem connecting the rete mirabile to the host vein (fig 2C). The minimal hydrostatic pressure gradient thus available to drive perfusion through the dilated veno-venous plexus accounts for the slow flow of dye observed during fundus fluorescein angiography (FFA), ${ }^{8}{ }^{17}$ a property overshadowed by the profuse dye leakage. Where adjacent networks anastomose, however, vascular remodelling can be envisaged to redirect and accelerate the flow and to render any one (or even both) of the connecting channels in any VNP redundant.

\section{HYPOXIC UPREGULATION OF ANGIOGENIC GROWTH FACTORS AND THEIR RECEPTORS}

In 1948, Isaac Michaelson ${ }^{18}$ reported his Indian ink injection studies on the fetal retinal vasculature. He observed a periarterial capillary-free zone as vascular networks emerged from the venous side of the developing circulation and felt this implied a gradient of progressive retinal hypoxia with increasing distance from the artery. This led to his presenting his celebrated hypothesis implicating a hypoxia-inducible "environmental factor" that controls not only embryonic vessel formation (either de novo from precursor cells, "vasculogenesis", or from pre-existing vessels, "angiogenesis") but also pathological neovascularisation of the mature retina.

Michaelson suggested that, in PDR, the soluble mediator is secreted by extravascular retinal components challenged by hypoxia from a circulatory disturbance yet to be discovered. Moreover, in the published discussion of his presentation, he introduced the concept of "remote" neovascularisation by postulating that diffusion of the same molecule throughout the vitreous cavity, overspilling into the posterior and anterior aqueous chambers, stimulates rubeosis iridis. Iris neovascularisation and formation of ODNVs and PRNVs are now believed to involve recruitment of circulating endothelial progenitor cells ("adult vasculogenesis") as well as angiogenesis. ${ }^{19}$

Extracts of vitreous gel removed from eyes with PDR induce directional vessel growth in vivo in the chick chorioallantoic membrane $^{20}$ and are a ready source of candidates for Michaelson's "factor x". Angiogenic molecules thus far isolated include insulin-like growth factor 1, endothelial cell-stimulating angiogenesis factor, fibroblast growth factor, vascular endothelial growth factor (VEGF), placental growth factor (PlGF), hepatocyte growth factor, erythropoietin and angiopoietin. ${ }^{21-29}$ The vitreous concentration of any such factor at any one time is the resultant of its retinal release set against its diffusion utilisation, enzymatic destruction and sequestration on cell membranes or extracellular matrix (ECM) components. The endocrine "growth hormone/insulin-like growth factor 1 axis" is also crucial to intraocular neovascularisation, witness the effect of pituitary ablation, while vitreous levels of connective tissue growth factor reflect the extent of associated fibrosis. $^{30} 31$

The primacy of the role of VEGF in PDR is suggested, first, by its generic properties in relation to Michaelson's "chemical mediator hypothesis". VEGF receptors (VEGFRs) are hyperexpressed on 

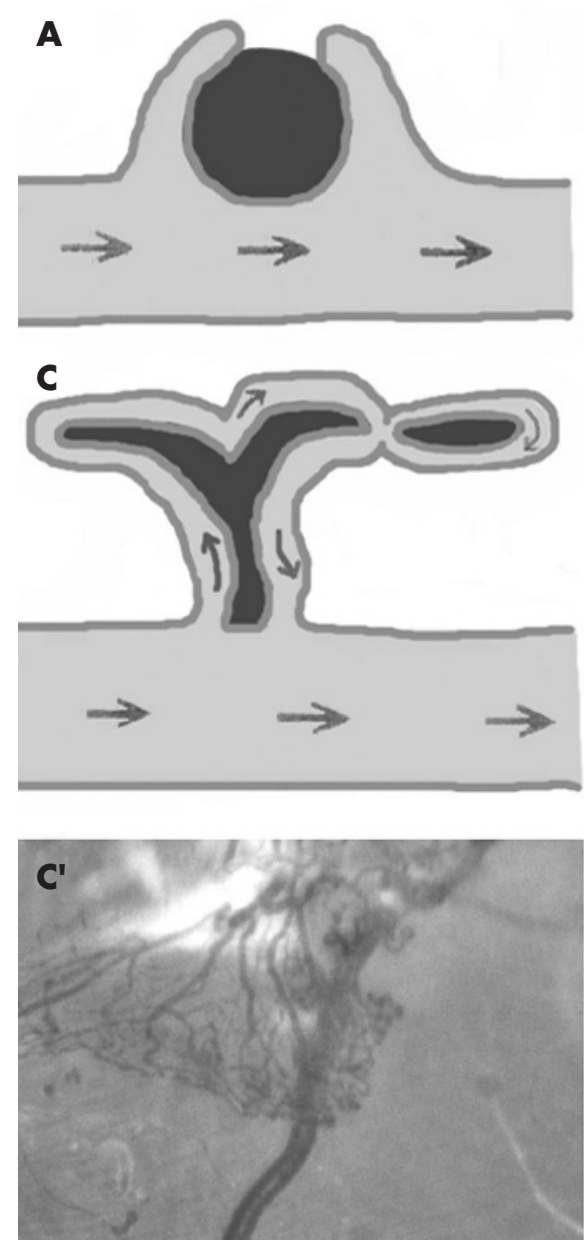

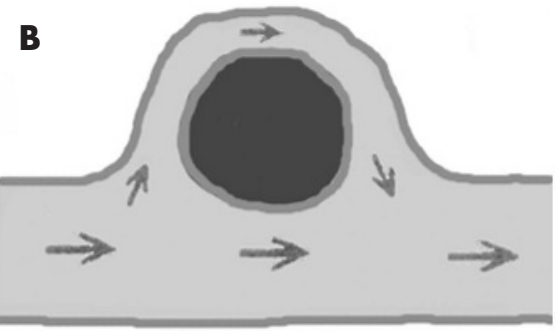

D
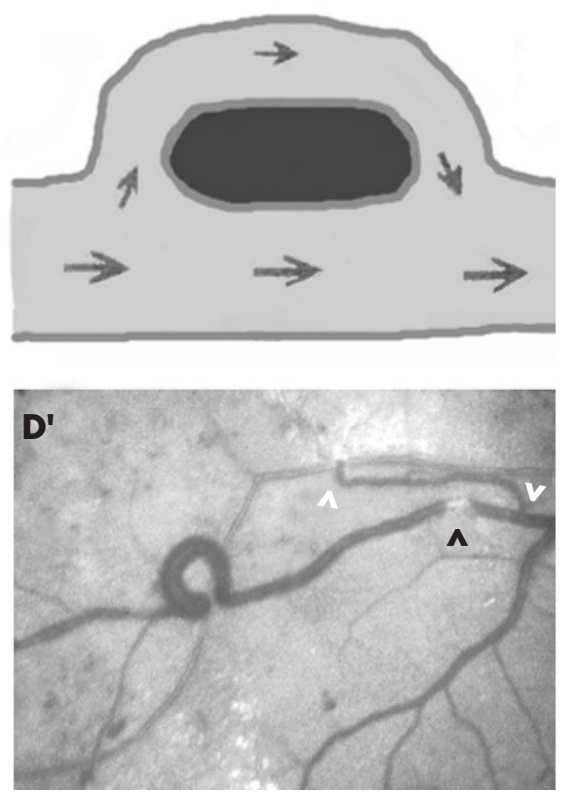

Figure 2 Microvascular intussusception. (A-D) Diagrams after Patan et al:;3 arrows indicate direction of blood flow. Lumen (grey) of the parent vein evaginates (A) around a partial interstitial septum (black) forming a perfused loop in the vein wall (B). Lateral intussusception creates a vascular network or rete mirabile connected to the parent vein by afferent and efferent channels within the venous neovascular peduncle (C). Parallel or lengthwise intussusception elongates the loop and creates venous reduplication (D). (C') Small rete mirabile. $\left(D^{\prime}\right)$ Inflated omega $(\Omega)$ loop spanning an arteriole; arteriovenous anastomosis (between white arrowheads) and putative venous partitioning (black arrowhead). retinal vascular endothelial cells, and synthesis of VEGF protein (and that of its receptors) is modulated by the local oxygen tension..$^{32-34}$ The efficient cellular secretion of all its isoforms and free diffusibility of smaller isoforms further combine to make VEGF an ideal candidate molecule. Secondly, indirect evidence of a substantial role for VEGF in PDR includes its involvement in angiogenesis in hypoxic tissues and in tumours generally, whether through intussusception or sprouting or both. ${ }^{13}{ }^{14}$ Moreover, intravitreal injection of VEGF induces rubeosis iridis and retinal MVI that penetrates the ILL, while other types of experimental ocular angiogenesis can be inhibited by targeting action of VEGF receptor. ${ }^{35}{ }^{36}$

Human histopathological examination provides a third and direct source of evidence that VEGF is a vital mediator in PDR (fig 3). Retinal VEGF immunostaining increases with increasing severity of retinopathy, ${ }^{38}$ but this is not a sufficient indication of the protein's role. Increased bioactivity depends on the ligand's access to, and the density and avidity of, the relevant receptors on its target cells. A spatial and temporal correlation can be shown between the retinal expression of VEGF and its main receptor, VEGFR2, as the retinopathy progresses..$^{38}$ Eventually, the VEGF/VEGFR2 system is massively expressed within and immediately surrounding those veins, and giving rise to the new vessels as well as, in continuity with the preretinal neovasculature itself. Similar spatial and temporal coupling applies to the PIGF/VEGFRl system that has been implicated in adult vasculogenesis. ${ }^{26}{ }^{39}{ }^{40}$ Molecular signals from other participating systems no doubt interact to stimulate, modulate and terminate the various stages of MVI.
Once new vessels penetrate the ILL, their further ramifications are orientated parallel to the retinal surface, and especially towards the hypoxic retinal territories (fig 1A,B). Such "directionality" is probably determined by the distribution of VEGF in the ECM, as either variable concentrations of soluble isoforms in the gel or deposits of large heparin-binding isoforms on vitreous fibrils. Specialised migrating endothelial cells or "tip cells" in the vanguard of the neovascular plexus have been implicated in rete expansion along these putative chemotactic gradients. ${ }^{41}$ A truncated "cartwheel" centred on a VNP is the characteristic angiogenetic pattern in PDR, while the delicate loops at the distal limit of vasoproliferation are sometimes augmented by aneurysms or replaced by marginal vessels (fig 1). ${ }^{158}$

\section{INNER RETINAL ISCHAEMIC TOPOLOGY AND RETINAL VENOUS ARTERIALISATION}

In 1950, Norman Ashton ${ }^{42}$ described an Indian ink injection technique that differed in detail from that used by Michaelson. Using this protocol, Ashton illustrated, for the first time, the archetypical pattern of ischaemia in diabetes wherein broad swathes of capillary non-perfusion affect the mid-peripheral and peripheral retina (fig 4A). However, the significance of this capillary dropout, affecting $>80 \%$ of the capillary net, was overlooked because the specimen was considered incompletely injected. This was despite successful filling of the entire macular capillary bed and the medium-sized arterioles and venules pursuing a meridional course between the equator and optic disc nasally and the major vascular arcades temporally. As 


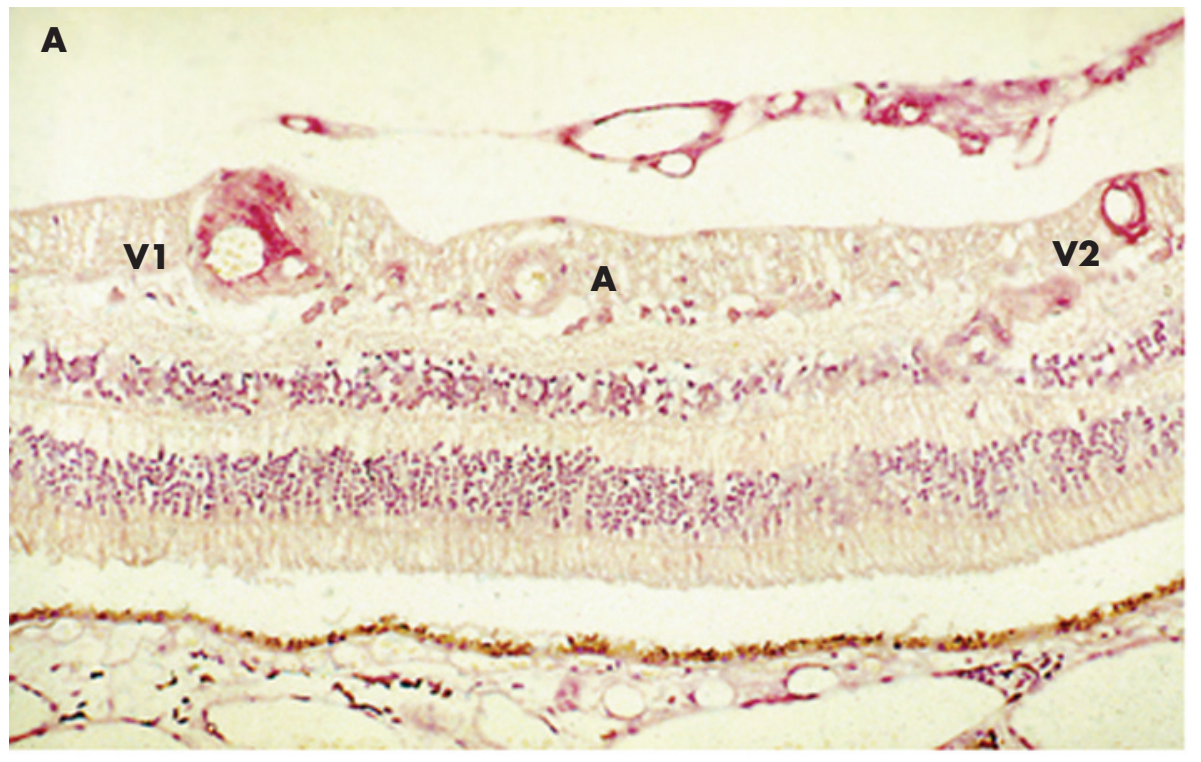

Figure 3 Immunochemistry and ultrastructure in proliferative diabetic retinopathy (PDR). (A) Retina with PDR stained for vascular endothelial growth factor protein; intense staining of preretinal new vessels and retinal veins $\left(V_{1}\right.$ and $\left.V_{2}\right)$ in cross-section, but the retinal artery $(A)$ is unstained. Loss of ganglion cell layer, inner nuclear layer and part of the outer nuclear layer midway between $A$ and $V_{2}$ (representing "core of infarction"). (B) Retina with PDR stained for vascular endothelial growth factor receptor 1 ; intense staining of endothelium and adventitia of intraretinal vein and preretinal neovasculature in continuity. (C) Scanning electron microscopy of an excised segment of fibrovascular epiretinal membrane (ERM); smooth undersurface interrupted by vessel. $(D, E)$ Glial fibrillary acidic protein staining of the retina with PDR (D) and excised fibrovascular ERM (E): glial component of peduncle, stroma and inner (vitreous) surface lamina (figs $3 A, B$ and $D$ from Boulton et $a)^{\beta 8}$ and Smith et $a^{\beta 9}$ ).

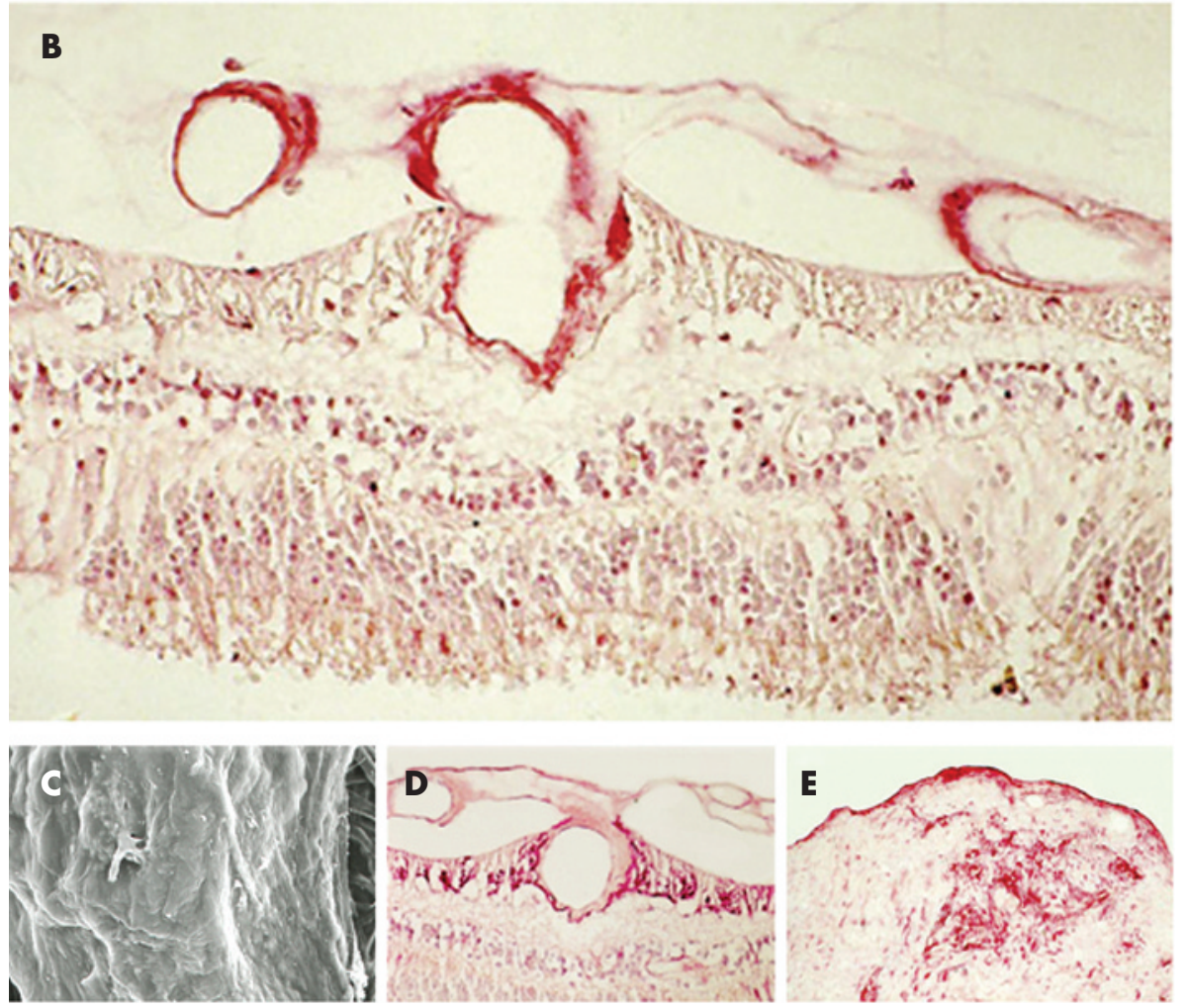

a result, Ashton's 1953 publication ${ }^{43}$ is generally cited instead as the first to implicate capillary closure in the pathogenesis of PDR.

Retinal digest and in vivo studies subsequently confirmed that capillary non-perfusion in diabetes varies in extent from closure of individual capillaries to obliteration of the whole capillary net apart from that serving the immediate peripapillary retina.$^{44}$ It was not until 1981, however, that FFA montages from Shimizu and colleagues ${ }^{45}$ displayed the same ischaemic topology as that illustrated by Ashton 31 years earlier, and showed that this is by far the most common pattern in PDR. The oval interface between perfused and non-perfused retina is typically located just external to the temporal vascular arcades and nasal to the disc, and is penetrated by multiple arterioles and venules radiating into the ischaemic periphery. There the vessels are linked by arteriovenous anastomoses representing dilated capillary connections ("preferential channels") and/or by de novo establishment of direct communications ("fistulae" $e^{\prime \prime}$ at arteriovenous crossings. ${ }^{43}{ }^{45-48}$ Arteriovenous shunting and vascular dilatation presumably explain the modesty of the reduction in volumetric retinal blood flow seen in $\mathrm{PDR}^{49}$ notwithstanding the gross tissue hypoperfusion, and probably cause retinal venous hypertension.

Shimizu supported Ashton's hypothesis that the wholesale obliteration of the capillary bed reflects expansion of the periarterial capillary-free zone and coalescence of smaller 

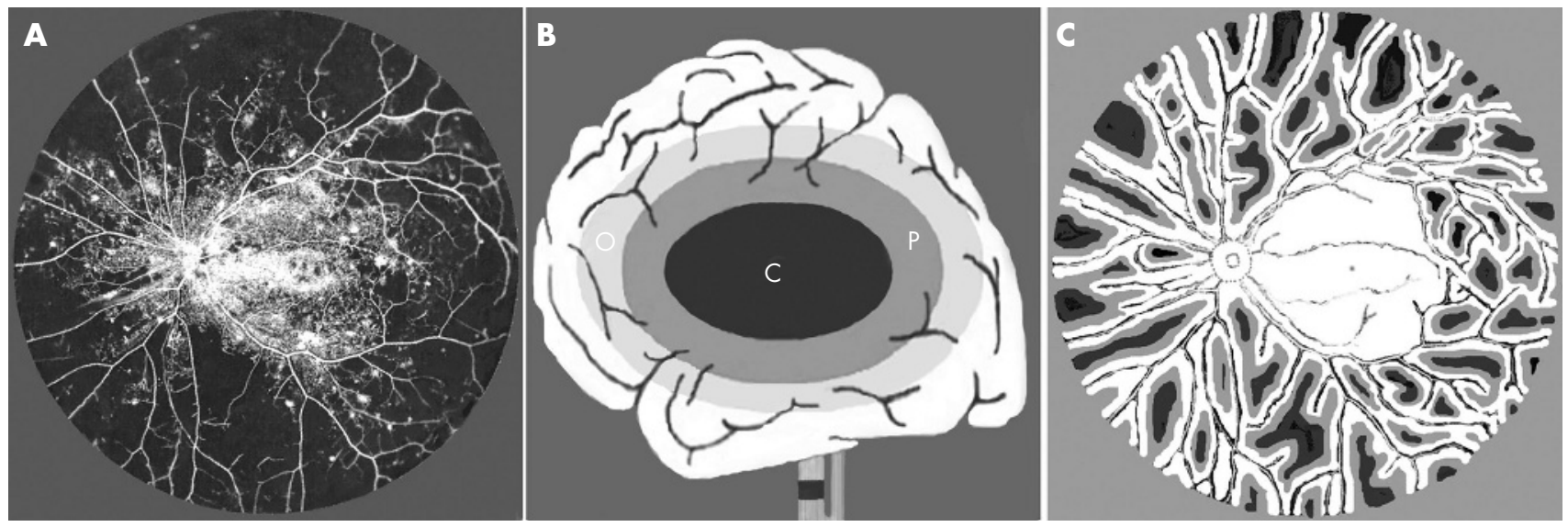

Figure 4 Topography of ischaemia. (A) Ashton's 1950 Indian ink injection study 42 of postmortem eye from a 71 -year-old patient with diabetes of 26 years duration; illustration scanned and positive-to-negative inverted to simulate fundus fluorescein angiography. Extramacular capillary closure through $360^{\circ}$; medium-sized arterioles and venules radiate and anastomose across mid-peripheral retina. (B) Diagram after Kidwell et al ${ }^{61}$ showing the consequences of internal carotid artery occlusion in cerebral grey matter. Ischaemic penumbra (P) interposed between core of infarction (C) and zone of benign oligaemia (O). (C) Hypothetical map of diabetic inner retinal grey matter penumbra (based on histopathological and visual field data) superimposed on vessel topology of Ashton's $1950{ }^{43}$ preparation; well-oxygenated tissue (white), penumbra (grey) and infarct (black).

ischaemic territories. ${ }^{43} 45$ Arteriolar occlusion by integrinmediated leucocyte entrapment is gaining acceptance as the underlying mechanism. ${ }^{50}$ The extent of capillary dropout on FFA is greatest in eyes with rubeosis iridis, and greater in eyes with ODNVs than PRNVs alone. ${ }^{45}$ Such "proportionality" implies that, for an angiogenic response to be mounted, agonists such as VEGF must exceed a threshold intraocular concentration, while a sufficient density and avidity of angiogenic receptors is induced in the retinal, disc and iris vasculature. Panoramic FFA also demonstrated a topographical relationship between the posterior margin of mid-peripheral capillary closure and sites of neovascular outgrowth from veins in the posterior pole. ${ }^{45}$ Like "directionality", such "proximity" had been much more obvious in well-circumscribed retinal ischaemia, as after branch vein occlusion. ${ }^{51-53}$ In diabetes, proximity to extensive capillary non-perfusion is a property also shared by venous coils and omega loops. ${ }^{54} 55$

\section{MISERY PERFUSION AND PENUMBRAL MODULATION OF PRERETINAL ANGIOGENESIS}

In 1956, George Wise pondered the neuroglial disturbances arising within inner retina affected by ischaemia, vasodilatation and neovascularisation. ${ }^{6}$ He surmised that a state of "relative anoxia" follows capillary or venous obstruction and that the cells secrete "factor $\mathrm{x}^{\prime \prime}$ as a byproduct of their altered metabolism. By contrast, cell death from "anaemic infarction" after occlusion of the central retinal artery (CRA) precludes production of angiogenic molecules, as does reperfusion of surviving cells or those involved in tissue repair. Wise then extended his "critical hypoxia hypothesis" to include retinal detachment, separation of the photoreceptors from the choroid being thought to induce subretinal neovascularisation. ${ }^{85}$ More recently, the onset of retinal detachment in PDR has been linked to rapidly accelerating rubeosis iridis. ${ }^{57}$

Studies of retinal VEGF elaboration using in situ hybridisation support Wise's concept. Although VEGF message wasn't noticeably different from normal in eyes with background retinopathy, heightened expression of VEGF mRNA was seen in parts of the ganglion cell layer and/or inner nuclear layer in eyes enucleated for rubeotic glaucoma. ${ }^{58} 59$ In eyes with retinal detachment, VEGF message was also increased in the outer nuclear layer.
Wise's hypothesis can be reformulated by borrowing the notion of "misery perfusion" following cerebrovascular occlusion and applying it to the hypoxic hinterlands of the diabetic retina. In acute cerebral ischaemia, a core of irreversible grey matter infarction is often surrounded by a zone of hypoxic but viable tissue (the "penumbra") that is itself surrounded by oligaemic tissue under no immediate threat of damage (fig 4B). ${ }^{60}{ }^{61}$ Within the penumbra, the precarious balance of oxygen supply and consumption is reflected in metabolic downregulation but enhanced oxygen extraction from blood still circulating through the tissues (a property exploited in positron emission tomography). Here, secretion of growth factors such as VEGF and angiopoietin, and upregulation of their receptors induce both neuroprotection and angiogenesis. ${ }^{62-65}$ The penumbral neurons are "silent" but may escape infarction and recover their function if clot lysis, collateralisation revasculansation or endarterectomy enables tissue reperfusion. Otherwise, especially where the penumbra abuts the necrotic core, neuroprotection fails, cellsapoptose and the infarct expands.

Acute retinal arterial occlusions are seldom complicated by neovascularisation, ${ }^{6866}$ but nonetheless they reveal a potential for tissue preservation and rescue. Thanks to oxygenation from the choroid, for example, the peripheral retina often survives CRA occlusion, allowing retention of the associated visual field or its early restoration. ${ }^{67-69}$ Reperfusion through the CRA probably contributes to this functional recovery and freedom from neovascular sequelae. When the CRA is only partially obstructed, tissue viability is also maintained posteriorly and extends peripherally as a mantle around vessels with a modicum of retained circulation..$^{70-72}$ Oxygen diffusion from these vessels and from the choroid underlies the creation of a complex grey matter penumbra (GMP) surrounding a peripapillary zone of benign oligaemia. This is associated with retinal venous cyanosis and visual impairment, but remarkable functional recovery follows restoration of the inner retinal circulation. A persistent GMP and intraocular neovascularisation characterises chronic panretinal hypoperfusion from carotid occlusive disease, ${ }^{672}$ but rubeosis iridis and ODNVs may regress within hours of endarterectomy. ${ }^{73}$

The angiogenic response in PDR parallels that induced by chronic panretinal hypoperfusion, or evolving within a cerebral penumbra. Since there is no tissue reperfusion capability after 
diabetic capillary closure other than that sometimes ascribed to intraretinal microvascular abnormalities, ${ }^{74}$ sources of inner retinal oxygenation are limited to the vitreous, the choroid and blood shunting through the medium-sized radiating anastomosing vessels (RAVs). As with CRA occlusion, a marked reduction is seen in the neuronal population of the ganglion cell layer and inner nuclear layer, together with a variable degree of gliosis. ${ }^{75}{ }^{76}$ However, sparing of a tissue mantle around the RAVs (fig 3A) enables some of the neurons to remain functional, ${ }^{76}{ }^{77}$ and heightened VEGF message in a perivascular distribution has also been illustrated..$^{59}$ This supports the hypothesis that RAVs are major determinants of GMP topography (fig 4C).

According to Davis, spontaneous regression of neovascularisation, part of the natural history of PDR, implies retinal ischaemia that is "too severe" to maintain vessel growth. ${ }^{15}$ Put another way, the angiogenic GMP may eventually be subsumed into the core of infarction owing to RAV occlusion and/or progressive choroidopathy. Similarly, after scatter photocoagulation, neovascular regression may follow the apoptotic demise of growth factor-secreting cells in the inner retina owing to choriocapillaris occlusion and reduced choroidal oxygenation. ${ }^{78}$ Alternatively, thermal destruction of the highly energetic photoreceptors, and the lower energy consumption of the glia that often replace them, might over-ride such influences and improve oxygen flux from the choroid. ${ }^{79}$ No concomitant neuronal rescue is evident, however, field constriction rather than functional gain following scatter photocoagulation.

Whichever route is taken in exiting from the GMP (whether via necrosis through apoptosis or rescue through reoxygenation), and whether this follows photocoagulation or occurs spontaneously over time, the outcome is the same. Neovascular regression is accompanied by downregulation of VEGF/VEGFR2 and PIGF/VEGFRl in the retina and vitreous, ${ }^{25} 263839$ reduced arterial diameters and volumetric blood flow, ${ }^{79}$ and reversal of venous beading and loop formation. ${ }^{55}$ Equatorial and postoral scatter laser is especially beneficial in attenuating the overall angiogenic drive, ${ }^{80} 81$ presumably by addressing the peripheral GMP sustained by the choroid.

\section{NEOVASCULAR BUDDING AND BIOMECHANICAL ACTIVATION OF ANGIOGENESIS}

In 1964 and 1970, John Dobree reported his longitudinal studies of PDR using 3-monthly fundus photography. ${ }^{72}$ Some of the neovascular lesions were at an early "naked" stage of development, whereas others within the same eye had regressed or fibrosed, suggesting that they were primarily responding to local retinal conditions rather than systemic changes. ${ }^{7}$ With Enid Taylor, Dobree then pinpointed sites of discrete neovascular outgrowth and showed that most PRNVs arise from retinal veins, only $20 \%$ deriving from the capillary bed. These locations had a composite distribution that was C-shaped and extramacular, sparing the temporal raphe. ${ }^{82}$ In preproliferative retinopathy, cotton wool sentinels in a similar distribution evolve proximate to the same ischaemic margin. ${ }^{17283}$

Taylor and Dobree went on to demonstrate that the great majority of neovascular outgrowths are located on either the peripheral or the disc side of arteriovenous crossings, as later confirmed by FFA. ${ }^{82}{ }^{45}$ They surmised that the site of venous budding might therefore reflect "a localised disturbance in haemodynamics". This chimes with contemporary views on the pathogenesis of MVI in that, using the chick chorioallantoic membrane and other models, endothelial gene expression has been shown to be powerfully modulated by haemodynamically generated stimuli. ${ }^{13} 8485$ The "biomechanical stress hypothesis" so derived links growth factor receptor expression in the vein walls to venous hypertension and/or flow disturbances from arteriovenous shunting.

Not all eyes developing PDR manifest clinically obvious changes in the retinal veins, ${ }^{1}$ but the transparent tissue envelope around the expanded red cell column usually develops a series of nodes (venous beading), and staining is evident on FFA, mirroring Ballantyne's phlebosclerosis (fig 5). Bleb-like buds with enhanced staining then emerge near arteriovenous crossings and/or at points of venous confluence or preferential channel insertion, and microloop formation is occasionally identifiable. ${ }^{8}$ Hyperfluorescent patches evolve thereafter, signifying neovascular endothelial modulation by the vitreous ECM once the ILL has been penetrated (fig 5A).

Remodelling within an expanded rete mirabile can result in channels whose width exceeds that of the retinal veins, whereas similarly wide, straight vessels sometimes connect host veins to distant preretinal neovascular networks. ${ }^{15}$ These afferent and efferent "feeder" vessels represent extended VNPs and often originate at arteriovenous crossings (fig $1 \mathrm{~B}$ ). Bek ${ }^{9}$ reported that the topographic relationship between venous loops and arteriovenous crossings is less remarkable. However, even if such loops arise at some distance from a crossing, serial sectioning may show their interconnection through a segment of venous reduplication. ${ }^{86}$ Furthermore, distended omega loops spanning arteriovenous crossings (fig 2 $\mathrm{D}^{\prime}$ ) can sometimes be shown to be arterialised on $\mathrm{FFA}^{8}$ suggesting that MVI underpins arteriovenous fistula formation.

\section{VITREORETINAL NEOADHESIONS AND ECM MODULATION OF ANGIOGENESIS}

In 1965/6, stereoscopic studies of the natural history of PDR were reported by Matthew Davis ${ }^{87}$ and Felipe Tolentino et al. ${ }^{88}$ Using indirect ophthalmoscopy and slit-lamp biomicroscopy, they described a precise correlation between sites of neovascular projection into the vitreous cavity and the establishment of exaggerated vitreoretinal adhesions. Clinically, the earliest new vessels appeared to be sandwiched between the retina and the posterior hyaloid membrane (PHM), whose local separation from the ILL was considered important in stimulating vasoproliferation. The vessels were thought to adhere progressively to the PHM thereafter.

Subsequent histopathological studies suggested that PRNVs become "incarcerated" within attached cortical vitreous from the outset. ${ }^{89}{ }^{90}$ Leaking plasma components such as fibrin and fibronectin are then added to the ECM which, like the ILL, is subjected to proteolytic modification by the expanding neovasculature. The balance of pro-angiogenic and anti-angiogenic influences therefore tips in favour of vasoproliferation through retinal overproduction and intravitreal accumulation of molecules such as VEGF, and also through sequestration or degradation of vasoinhibitory molecules in the gel. The latter include pigment epithelium-derived factor (which cleaves VEGFR1) and two molecules colocalising within the vitreous cortex, endostatin and opticin..$^{9-94}$

Foos ${ }^{95}$ drew parallels between the vitreoretinal neoadhesions of PDR and the normal developmental vitreopapillary adhesion, wherein glial cells at the disc margin incarcerate vitreous fibrils. An intimate horizontal conjunction indeed develops between the vascularised epiretinal membranes (ERMs) and the vitreous ECM, but vitreoretinal connectivity in PDR also depends crucially on the integrity of the VNPs. Otherwise called "vascular pegs" or "glial nails", these structures are exposed when vertically orientated microscissors are used to "segment" a coalescent fibrovascular ERM, thus separating small tissue islands from one another and isolating the VNPs. Alternatively, horizontally orientated scissors are used to sever the VNPs"membrane delamination" (fig 6). ${ }^{96}$ Unfortunately, en face 

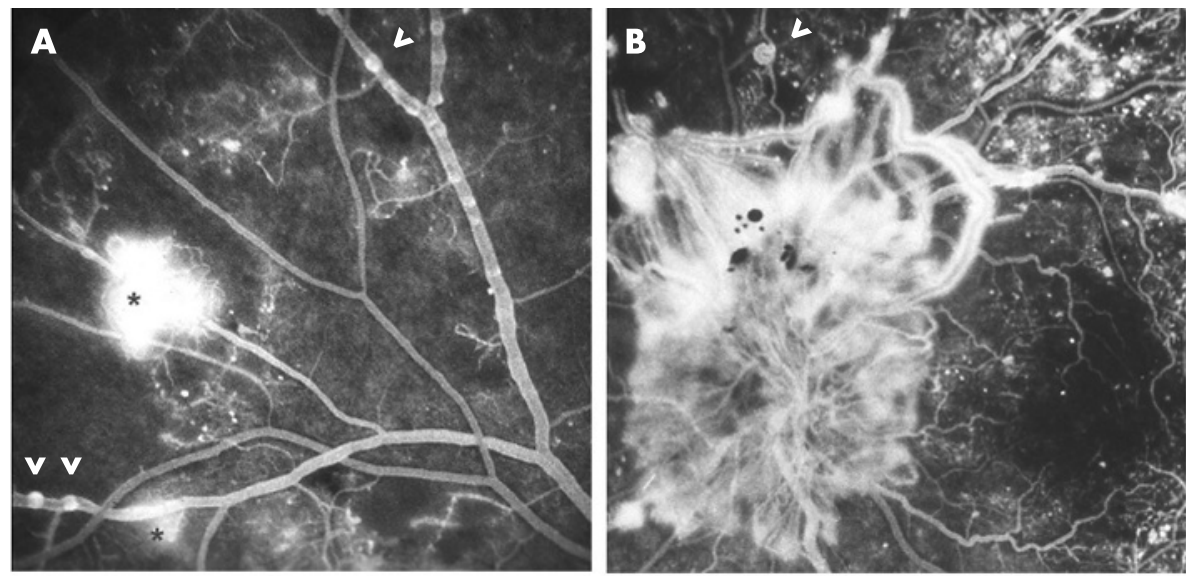

Figure 5 Fundus fluorescein angiography. (A) Against a backdrop of capillary closure, staining of venous walls reveals nodes and bleb-like buds (arrowheads) giving way to circumscribed hyperfluorescence (asterisks) indicating neovascular penetration of inner limiting lamina. (B) Delicate rete of optic disc new vessels, wide neovascular channels and a microloop (arrowhead). (C) Dye leakage from arterialised rete within detached posterior hyaloid membrane; rete connected to retina by extended peduncle traversing retrohyaloid space (between arrowheads). (D, E) Two abortive neovascular outgrowths, each showing a convectional plume of dye (D) in vitreous cavity fluid of a vitrectomised eye and (E) in retrohyaloid fluid of an eye
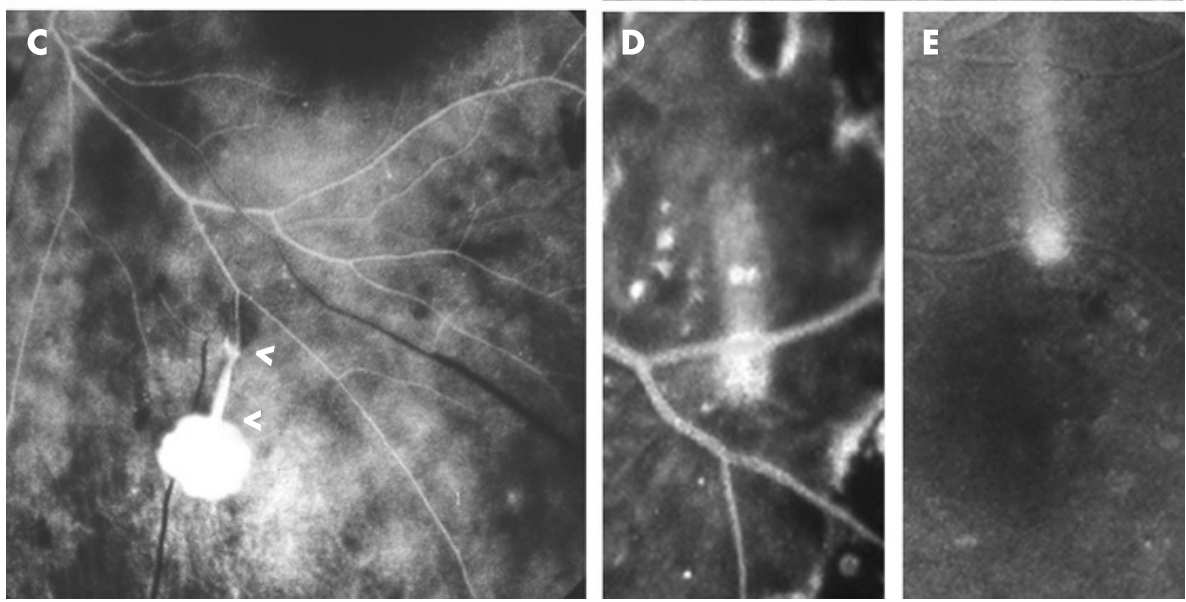
with PVD.

biomicroscopic views of fully established ERMs may give little indication of the density of their peduncular retinal attachments, and therefore what surgical difficulties to anticipate.

The openings in the ILL that accommodate the VNPs also allow Muller's glia to penetrate and gain anchorage within the fibrovascular tissue, ${ }^{39} 7590$ sometimes forming a "pavement" over its inner surface similar to that covering simple age-related ERMs (fig 3D,E). ${ }^{90} 9597$ This neuroectodermal component may be the foundation for the surgical impression that established ERMs are more adherent than earlier proliferations ${ }^{57}$; it may reinforce the VNP in its role as the conduit for transmitting ERM contraction forces into the sustentacular architecture of the retina, and it may contribute to the persistence of vitreoretinal adhesion even after neovascular regression.

Most vascularised vitreoretinal adhesions can resist the forces of vitreoretinal separation, and ODNVs will augment the pre-existing vitreopapillary connection. Extension of PVD is constrained by "point adhesions" or by "zonal adhesions" from single or from multiple adjacent VNPs, respectively (fig 7). The adhesions eventually become isolated from one another and from the vitreous base while remaining interconnected through the detached PHM..$^{5355796}$ Associated elevation of the edges of the vascularised ERMs may be complicated by a "sudden spurt" or exacerbation of vasoproliferation along the contiguous $\mathrm{PHM}^{87}$ but whether such "neo-neovascularisation" occurs independently of tractional retinal detachment is uncertain (fig 7A). Myofibroblasts regularly proliferate and migrate anteriorly towards the vitreous base, however, their contraction immobilising and shrinking the PHM (fig 7B). The anteroposterior vitreoretinal traction thus generated may compound the tangential forces of ERM contraction in detaching the retina, but otherwise can lead to tractional retinoschisis ${ }^{98} 99$ or tractional extraction of a "lambda $(\lambda)$ vascular loop" from the retina (fig 7C).

Realisation that the vitreous ECM is a vital scaffold for preretinal angiogenesis began to dawn once it was appreciated that "flat" new vessels grow along horizontal planes defined by the cortical vitreous lamellae and become "forward" vessels only when that part of the cortical vitreous continuum, within which they are incarcerated, separates from the retina. This notion was underlined by the observation that no postbasal neovascular tissue reproliferates over the retina after vitrectomy, and that an established complete PVD protects against preretinal rete expansion..$^{57} 100101$ The requirement for an "ECM substrate" is now believed to be a generic property of angiogenesis, underwritten by specific integrins on the endothelial cells such as $\alpha_{v} \beta_{3}$ and $\alpha_{v} \beta_{5} \cdot{ }^{14}{ }^{102-105}$ As well as promoting cell adhesion to structural ECM components such as collagen and fibronectin, these transmembrane proteins are crucial to functional regulation of the neovascular endothelium-for example, through activating growth factor receptors (such as VEGFR2) within the plasmalemma while interacting with the ligand (VEGF) in the ECM.

Even in the absence of a vitreous substrate, a stunted form of neovascularisation sometimes appears on the retinal surface at the posterior margin of mid-peripheral ischaemia or from arteriovenous crossings in the macula. ${ }^{53} 106-108$ These abortive neovascular outgrowths are incapable of rete expansion, but their convoluted channels, blood-filled cavities and peduncular retinal connections are consistent with MVI. The epiretinal glomeruli are distinguishable from intraretinal lesions such as intraretinal microvascular abnormalities and "abortive foveal 


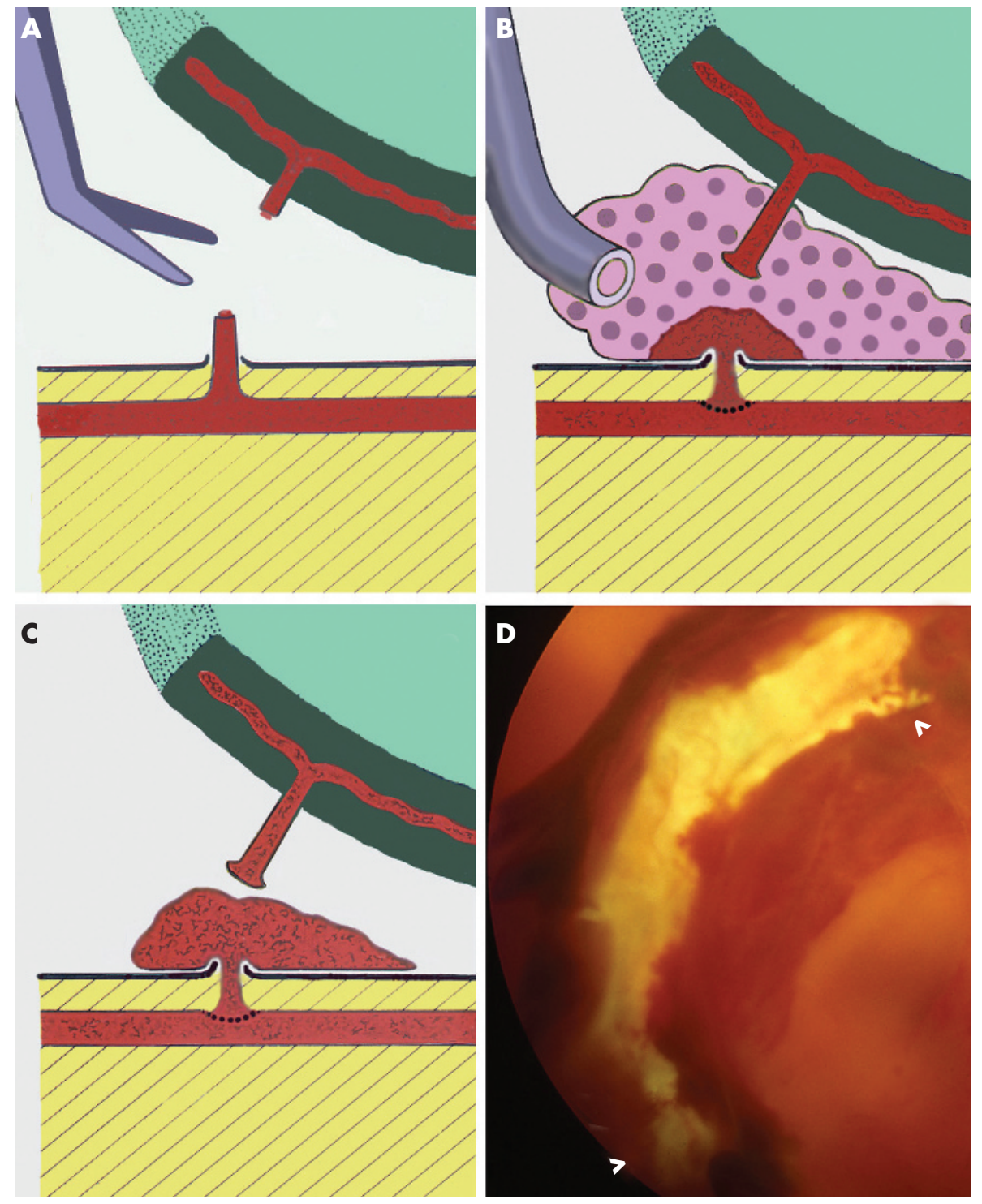

Figure 6 Delamination of fibrovascular epiretinal membranes (ERMs). (A) Diagram of scissors delamination; no untoward bleeding from the cut ends of venous neovascular peduncle. (B) Diagram of viscodelamination; avulsion of the venous neovascular peduncle from the retinal vein while injected viscoelastic constrains bleeding. (C) Diagram of spontaneous PVD and peduncular avulsion; blood clot on retinal surface (after McLeod and James ${ }^{110}$; for clarity, venous neovascular peduncles are depicted as containing only one channel linking rete to retinal vein). (D) Fundus photograph of left eye of a patient with PDR taken within $2 \mathrm{~h}$ of onset of vitreous haemorrhage; retrohyaloid blood clot beneath and surrounding fibrovascular ERM. Shrivelled segments of ERM where peduncles have avulsed and have no rete perfusion (arrowheads).

retinal neovascularisation"74 ${ }^{109}$ by the "smoke stack" leakage of dye wafting in the vitreal fluid on FFA (fig 5D,E); rubeosis iridis generates a similar convectional plume in the aqueous. ${ }^{83}$ This contrasts with the relative confinement of leaking proteinbound dye to the immediate vicinity of new vessels growing within cortical gel (fig 5A-C). Retrosilicone oil neovascularisation is an example of preretinal angiogenesis prospering in the absence of a vitreous substrate. The confines of the retrosilicone space apparently ensure a rich concentrate of growth factors and a self-perpetuating cycle of plasma leakage and deposition of alternative angiogenic substrates such as fibrin. ${ }^{5396110111}$

The limited availability of ECM substrates within the neuroretina probably explains the virtual absence of intraretinal revascularisation in PDR. However, in adults, a matting of collagen fibrils is secreted into the superficial retina at its extreme anterior limit. ${ }^{112} 113$ Provided RAVs extend to this remote location, therefore, new vessels can proliferate intraretinally before accessing the basal gel and anterior hyaloid alongside heterotypic fibrils that penetrate the postoral ILL and splice with those in the vitreous cortex (fig 8). Such "retrolental neovascularisation" or "anterior hyaloidal fibrovascular proliferation" first came to attention as a complication of vitrectomy in eyes with untreated peripheral retinal ischaemia and scleral buckling. ${ }^{96}{ }^{114}$ However, it is now evident that, irrespective of PVD or vitrectomy, a limited form of basal vasoproliferation is often present in eyes with rubeosis iridis in the guise of an oral ridge, best appreciated endoscopically. ${ }^{115}$

Stefansson et al" 116 have rejected the "vitreous substrate hypothesis", proposing instead that improved inner retinal oxygenation by fluid vitreous explains the absence of ODNVs and postbasal PRNVs after complete PVD or vitrectomy. However, although vitreous oxygenation can indeed protect the innermost ganglion-cell axons from ischaemia, ${ }^{72} 117$ the lower oxygen tension in diabetic vitreous will limit retinal oxygenation through this route. ${ }^{118}$ Moreover, the concentration of VEGF remains unchanged in the vitreous cavity after diabetic vitrectomy, so hypoxia within the inner retinal GMP presumably is not alleviated. ${ }^{119}$ Scatter endophotocoagulation is usually necessary, therefore, to counter anticipated complications (such as rubeosis iridis) arising from surgical interference with barriers to intraocular diffusion of angiogenic molecules. This is of particular concern in aphakic eyes and in phakic or pseudophakic eyes with incidental or intended breaches in the anterior hyaloid ("pseudo-aphakia"). ${ }^{81}$ 

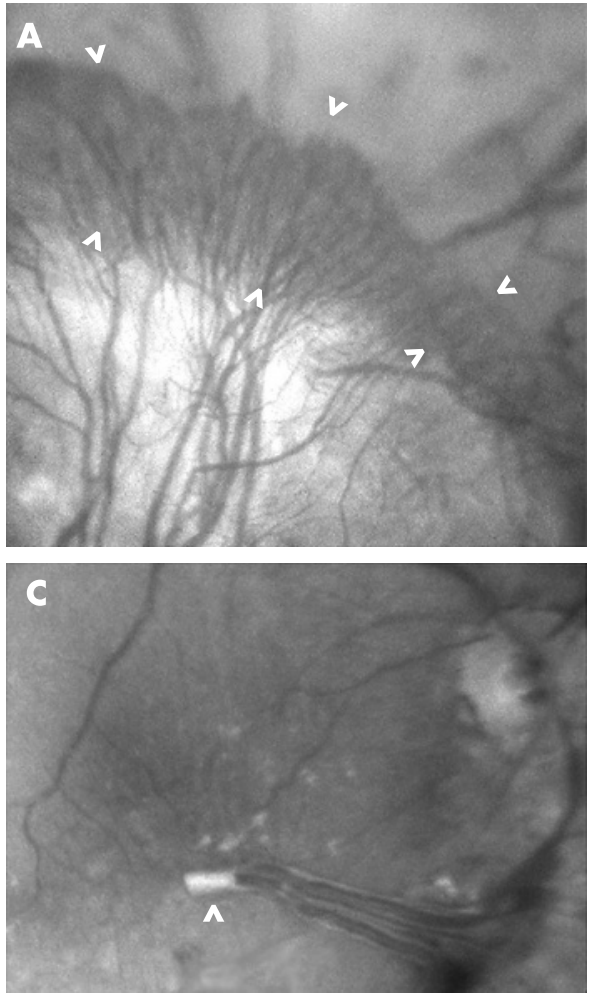

Figure 7 Fibrovascular epiretinal membranes (ERMs) and neovascular peduncles. (A) Brush of capillary loops (between arrowheads) proliferating along detached posterior hyaloid membrane (PHM) towards vitreous base; loops arise from edge of mature ERM causing underlying tractional retinal detachment. (B) Macrophotograph from a hemisected eye postmortem; incomplete detachment of vitreous with taut PHM; point adhesion of vitreous to retina through venous neovascular peduncles (VNP; arrowhead) and zonal adhesion over optic disc. (C) Macular retina after vitrectomy; amputated peduncle (arrowhead) at the apex of a drooping "lambda $(\lambda)$ vascular loop" comprising major inferotemporal vein and artery; these vessels were earlier "extracted" from retina by anteroposterior traction exerted through the VNP, which presumably originated near the region where the vessels were crossing. (D) Arc of completely avulsed and avascular ERMs (arrowheads) within detached vitreous cortex; retrohyaloid haemorrhage partially obscures retina nasal to disc.

\section{VENOUS PEDUNCULAR AVULSION AND VITREOUS HAEMORRHAGE}

The reports from Davis and from Schepens' group in 1965/6 also suggested a role for PVD in precipitating vitreous haemorrhaging, purportedly through its exerting traction on "unsupported" new vessels. ${ }^{87} 88$ Then, in eyes with dehiscences in the vitreous cortex, blood from the retrohyaloid compartment might penetrate into the vitreous gel. However, this hypothetical mechanism of haemorrhage induction has several shortcomings. First, the fragile PRNVs are presumed to coexist alongside vascularised adhesions capable of withstanding the forces of PVD and of transmitting tractional forces into the retina. Secondly, Ballantyne's histopathological observations and what is known about MVI combine to deny that PRNVs are ever "unsupported". ${ }^{9-12}$ Thirdly, haemorrhaging typically occurs during the later stages of PDR when PRNVs are entombed within fibrous tissue whose contraction contributes to the initiation of PVD. ${ }^{5}$

Defining the mechanism of haemorrhaging in PDR is problematic because blood immediately clots in front of the retina before lysing and dispersing (fig 6C,D). However, the physical consequences of PVD are revealed during the now largely obsolete microsurgical technique of "viscodelamination". Viscous injection between the PHM and retina elevates the ERMs and stretches the VNPs, facilitating en bloc disengagement of the vitreous cortex and ERMs from the retina. ${ }^{110}{ }^{120}$ As the controlled vitreoretinal separation proceeds, however, bleeding frequently occurs albeit the haemorrhage may be confined by the transparent viscoelastic and the induced ocular hypertension (fig 6B). The source of bleeding can then be identified as side-puncturing of the vein walls as VNPs are avulsed, so it is the retinal vein (rather than the preretinal neovasculature) that bleeds. VNP avulsion also complicates other microsurgical dissection techniques, whether ill-advised "peeling" of vascularised ERMs or, unintentionally, during segmentation or delamination.
This disruptive mechanism parallels Weiss ring formation during rhegmatogenous age-related $\mathrm{PVD}^{121}{ }^{122}$ and various degrees of ERM-retinal cleavage result. As noted, partial ERM avulsion will cause flat new vessels to become forward vessels (with or without neovascular exacerbation), but no bleeding arises without VNP avulsion (fig 7B). Rarely, the ERM becomes entirely disconnected from the retina other than through feeder vessels that traverse the retrohyaloid space and maintain rete perfusion (fig 5C). ${ }^{15}$ Complete ERM and peduncular avulsion (fig 7D) will result in haemorrhaging from the arterialised retinal veins, and empty "ghost vessels" may then be discernible within the aerialised ERMs embedded in the detached PHM. Most frequently, however, avulsion of part of a fibrovascular ERM, including one or more VNPs, will precipitate bleeding (fig 6C,D), while only the affected ERM segments undergo autoinfarction (assuming no rete anastomosis).

Vitreous haemorrhaging in PDR is thus an inherently selfhealing process. The venous bleeding point seldom leaks after puncture repair, and the non-availability of a vitreous substrate ensures that there is no further PRNV growth locally. Each haemorrhage is potentially a step towards eventual cessation of bleeding through completion of PVD or attainment of a residue of stable vitreoretinal adhesions that are not susceptible to avulsion. The absence of PRNVs or ODNVs from an eye containing a vitreous haemorrhage does not necessarily imply that PDR was not its cause (given the bleeding mechanism's ephemeral nature), while the discovery of new vessels in an eye with a vitreous haemorrhage does not dictate that these were responsible for the bleeding. Moreover, prior regression of neovascularisation and shutdown of rete perfusion does not guarantee protection from PVD-induced VNP avulsion and vitreous haemorrhaging. This has implications for defining clinical end points when assessing antiangiogenic treatments. 

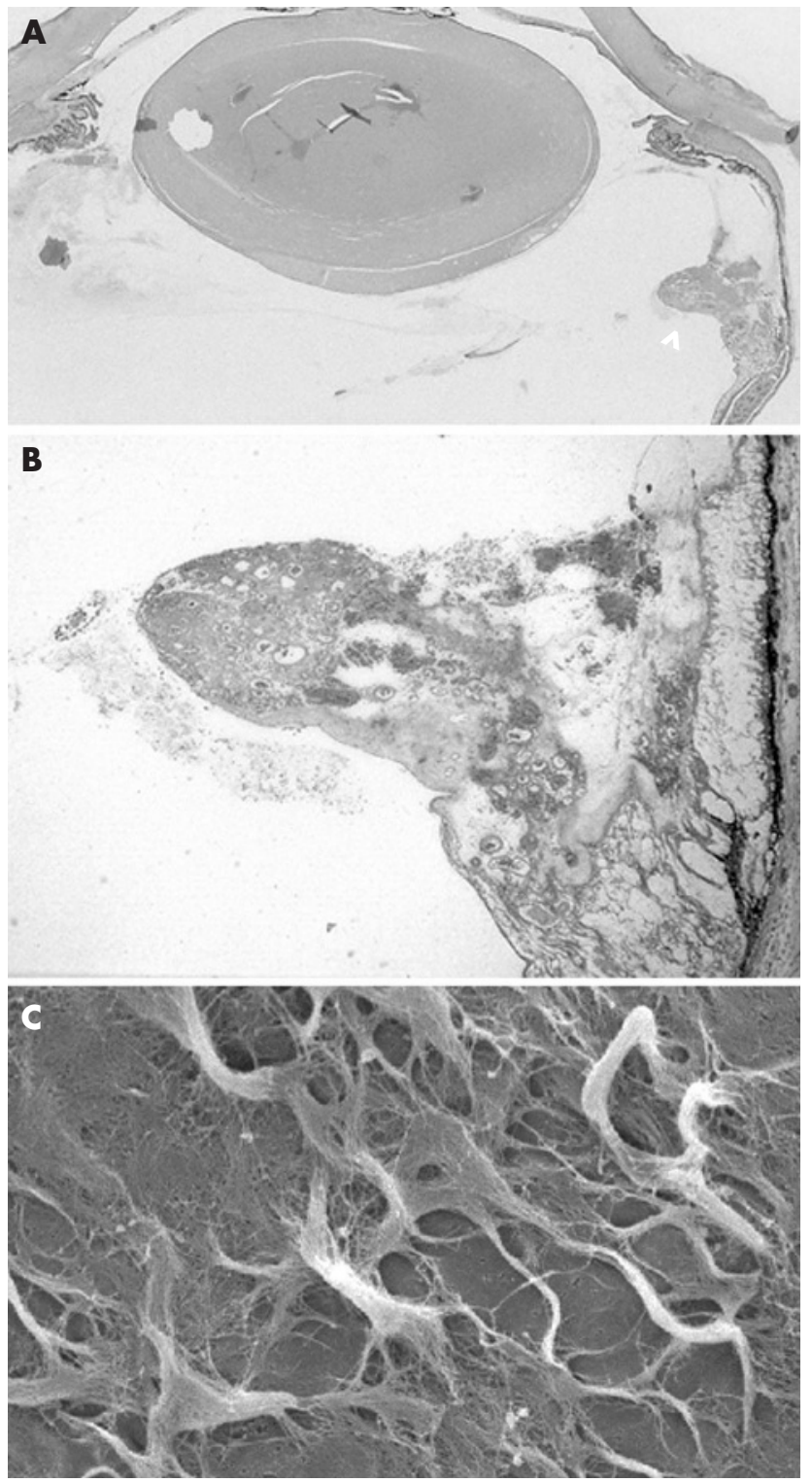

Figure 8 Basal vasoproliferation. (A, B) Sections from an otherwise unoperated eye excised for diabetic rubeosis iridis (courtesy of $\operatorname{Dr} R$ Bonshek). (A) Oral ridge of vasoproliferation (arrowhead) with detail (B) showing intraretinal vessels extending into basal vitreous. (C) Scanning electron microscopy of the undersurface of postoral ILL from normal eye after retinal cell digestion: angiogenic substrate from sublaminar matting of skeins of heterotypic fibrils (Wang et al). ${ }^{112}$

\section{PREPAPILLARY NEOVASCULARISATION AND OPTIC DISC STALK FORMATION}

The reports from Dobree and Taylor $(1964,1970)^{782}$ also demonstrated that ODNVs are generally more extensive than PRNVs when first identified in the clinic, and they evolve more rapidly through their developmental stages. FFA later showed that eyes with ODNVs have more extensive capillary closure than those with PRNVs alone, and that the posterior margin of mid-peripheral ischaemia is closer to the disc. ${ }^{45}$ Issues of proportionality and proximity aside, however, an exaggerated responsiveness of ODNVs has been postulated and variously ascribed to deficiencies in papillary tissue barriers (for instance, the thin ILL), to posterior drainage of vitreal fluid through the disc, or to "priming" by primary hyaloid remnants. ${ }^{6853} 123$ The abundance of prelaminar adventitial substrates, as well as haemodynamic factors such as the vascular waterfall within the central retinal vein (CRV) may also contribute. Occasionally, ODNVs seem to originate from the arterial supply to the optic nerve head rather than the CRV or its tributaries. ${ }^{55} 124125$

By definition, there is no secondary vitreous within the posterior expansion of Cloquet's canal that encloses the optic disc. An epipapillary angiogenic substrate nonetheless exists, enabling ODNVs to traverse the roof of the physiological cup after emerging from the disc $\operatorname{rim}^{1545}$ and also to form a rete, confined to the disc, in some eyes with complete PVD (as confirmed by smoke-stack disc fluorescence). ${ }^{107}$ Provided the vitreous remains attached to the peripapillary retina, however, ODNVs can undergo seemless, multidirectional, epiretinal extension using the secondary vitreous cortex as their substrate. Membranes containing ODNVs may then coalesce with juxtapapillary fibrovascular tissue arising from the retinal veins. Alternatively, feeder vessels with no connection to the underlying retinal vasculature supply preretinal networks that are exclusively papillary in origin (fig $\mathrm{IC}$ ). Vasoproliferation anteriorly along Cloquet's canal is an occasional accompaniment (fig 9A).

A stalk of fibrovascular tissue sometimes emanates from the disc in advanced PDR (fig 9B). Its formation can be attributed to the effects of PVD on juxtapapillary preretinal fibrovascular tissue that becomes forwardly disposed as the cortical vitreous separates from the retina. Fibrous contraction then creates a perpendicular structure with a horizontal rete at its point of attachment to the detached PHM. ${ }^{106}{ }^{126}$ The amount of associated bleeding (if any) reflects the number of retinal VNPs avulsed in the process, while spontaneous avulsion of ODNVs from the CRV also occurs occasionally (fig 9C,D). This entity is not to be confused with a "residual optic disc stalk" fashioned during segmentation of coalescent preretinal and prepapillary fibrovascular membranes, and which some surgeons prefer to avulse from the CRV and remove despite the risk of major haemorrhage. ${ }^{127}$

\section{CONCLUSIONS}

The clinical definition of PDR is that of preretinal and prepapillary vascular rete formation. This has the advantage of pragmatism in predicting PDR's haemorrhagic and tractional sequelae, but is arbitrary. Indeed, to distinguish PDR from "preproliferative" or "severe non-proliferative" retinopathy is to obscure their pathophysiological commonality. ${ }^{15}$ Reflecting the findings of Ballantyne $(1946)^{2}$ and Taylor and Dobree (1970), ${ }^{82}$ MVI is proposed as the fundamental link between venous budding, arteriovenous fistulae, VNPs, feeder vessels, rete mirabile, abortive neovascular outgrowths, venous reduplications and omega loops.

Michaelson (1948), Ashton (1950) and then Wise (1956) in turn predicted, demonstrated and then elucidated the intraretinal vascular changes underpinning the various vasoproliferative lesions of PDR. ${ }^{6} 1842$ By virtue of comparable gradients of hypoxia developing within the neuropile, diabetic capillary closure can be reconciled with cerebrovascular occlusions where penumbral neuronal rescue rather than angiogenic revascularisation was of prime interest until recently. Growth factor receptor upregulation in the retinal venous endothelium and its adventitia appears to be instigated by biomechanical stress as well as by the chronic GMP, and the RAVs have a role in generating both. A reduction in the volume of the GMP and neovascular regression follows tissue revitalisation by reoxygenation or, equally, tissue necrosis by apoptosis. In future, using physiological imaging to map the GMP may foster a more rational and potentially sight-enhancing approach to photocoagulation treatment. 

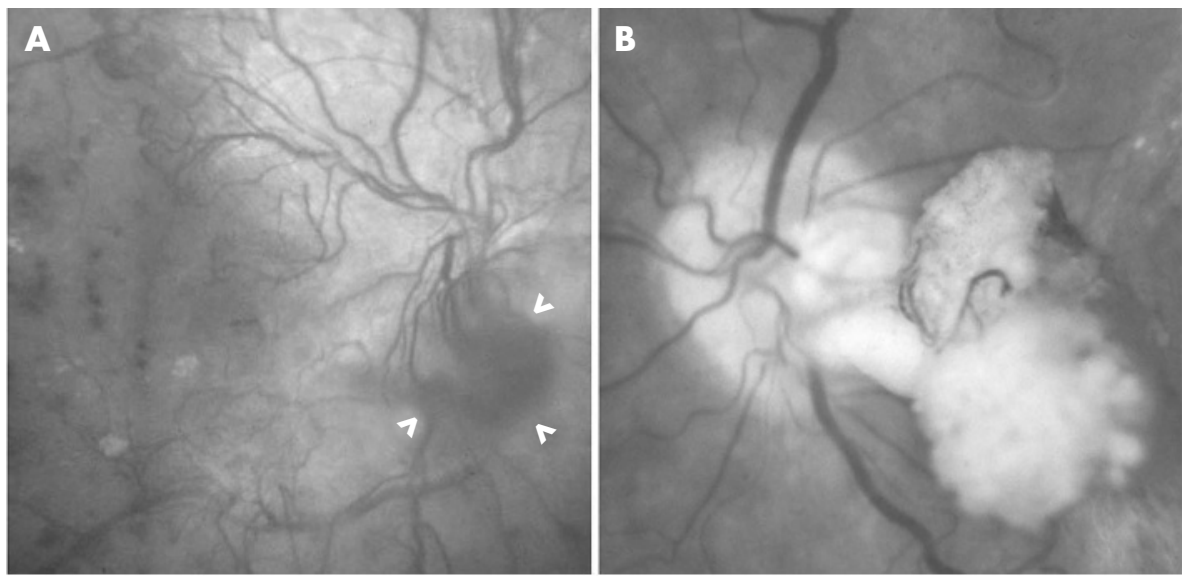

Figure 9 Fundus photographs of disc area. (A) Peripapillary fibrovascular epiretinal membrane and vascular rete (arrowheads) growing forwards along Cloquet's canal. (B) Vitrectomised eye with fibrovascular stalk in situ arising from inferotemporal disc rim. (C, D) Anteroposterior traction on "forward optic disc new vessels (ODNVs)" forming a short stalk $(C)$; same eye 1 week later after the clearance of intervening vitreous haemorrhage and showing complete avulsion of ODNVs from the central vein (D).
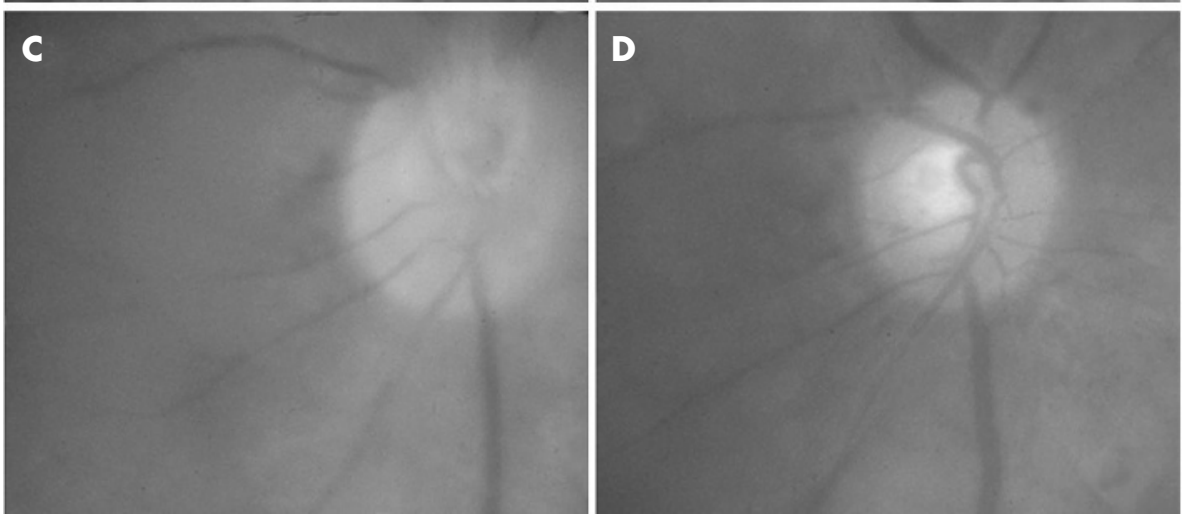

Stimulated by the observations of Davis (1965) and Schepens' group (1966), preretinal neovascularisation came to be recognised as being subject to the presence of an appropriate and accessible ECM substrate. ${ }^{87} 88$ Indeed, nowhere in the entire realm of clinical pathology is the importance of integrindependent vascular cell adhesion more clearly evident than at the postbasal vitreoretinal juncture. The virtual absence of retinal revascularisation after capillary closure, and variations in angiogenetic responses in the vitreous base and optic nerve head, are similarly explained. When the vitreous ECM detaches, however, the origins of the VNPs from the retinal veins are exposed as the points of greatest mechanical weakness within the neovasculature.

\section{ACKNOWLEDGEMENTS}

I thank JF Cullen, EM Kohner, RK Blach, PK Leaver, J Marshall, I Grierson, ME Boulton and PN Bishop for their inspiration and interaction in the field of diabetic eye disease. Grant support from The Wellcome Trust, British Diabetic Association, Guide Dogs for the Blind Association, Ross Foundation (Scotland) and the research endowment funds of Moorfields Eye Hospital and the Manchester Royal Eye Hospital is gratefully acknowledged.

Competing interests: None declared.

This is an update of the Duke Elder Lecture to the Annual Congress of the Royal College of Ophthalmologists for 1993.

\section{REFERENCES}

1 Davis MD, Blodi BA. Proliferative diabetic retinopathy. In: Ryan SJ, ed, Retina 3rd edn.St Louis:Mosby, 2001:1309-49.

2 Ballantyne AJ. The state of the retina in diabetes mellitus. Doyne Memorial Medal Lecture. Trans Ophthalmol Soc UK 1946;66:503-43.

3 Ballantyne AJ, Michaelson IC. Textbook of the fundus of the eye. Edinburgh, London: E\&S Livingstone, 1965.

4 Cogan DG, Toussaint D, Kuwabara T. Retinal vascular patterns IV. Diabetic retinopathy. Arch Ophthalmol 1961;66:366-78.
5 Davis MD. The natural history of diabetic retinopathy. Trans Am Acad Ophthalmol Otolaryngol 1968;72:237-40.

6 Wise GN. Retinal neovascularisation. Trans Am Ophthalmol Soc 1956:54:729-826.

7 Dobree JH. Proliferative diabetic retinopathy: evolution of the retinal lesions. Br J Ophthalmol 1964;48:637-49.

8 Wise GN, Dollery CT, Henkind P. The retinal circulation. New York: Harper and Row, 1971; 265-78, 422-53).

9 Bek T. Venous loops and reduplications in diabetic retinopathy: prevalence, distribution, and pattern of development. Acta Ophthalmol Scand 1999;77:130-4.

10 Dionov V, Schmid M, Tschanz SA, et al. Intussusceptive angiogenesis: its role in embryonic vascular network formation. Circ Res 2000;86:286-92.

11 Augustin HG. Tubes, branches and pillars: the many ways of forming a new vasculature. Circ Res 2001;89:645-7.

12 Burri PH, Hlushchuk R, Dionov V. Intussusceptive angiogenesis: its emergence, its characteristics, and its significance. Dev Dyn 2004;231:474-88.

13 Patan S, Munn LL, Tanda S, et al. Vascular morphogenesis and remodeling in a model of tissue repair: blood vessel formation and growth in the ovarian pedicel after ovariectomy. Circ Res 2001;89:723-31.

14 Bergers G, Benjamin LE. Tumorigenesis and the angiogenic switch. Nat Rev Cancer 2003:3:401-10.

15 Davis GE, Senger DR. Endothelial extracellular matrix: biosynthesis, remodeling, and functions during vascular morphogenesis and neovessel stabilization. Circ Res 2005;97:1093-107.

16 Williams JM Sr, de Juan E Jr, Machemer R. Ultrastructural characteristics of new vessels in proliferative diabetic retinopathy. Am J Ophthalmol 1988; 105:491-9

17 Gass JDM. Stereoscopic atlas of macular disease: diagnosis and treatment, 4th edn. St Louis: Mosby, 1997:516-22.

18 Michaelson IC. The mode of development of the vascular system of the retina, with some observations on its significance for certain retinal diseases. Trans Ophthalmol Soc UK 1948;68:137-80.

19 Grant MB, May WS, Caballero S, et al. Adult hematopoietic stem cells provide functional hemangioblast activity during retinal neovascularization. Nat Med 2002;8:607-12.

20 Hill CR, Kissun RD, Weiss JB, et al. Angiogenic factor in vitreous from diabetic retinopathy. Experientia 1983;39:583-5.

21 Grant M, Russell B, Fitzgerald C, et al. Insulin-like growth factors in vitreous. Studies in control and diabetic subjects with neovascularization. Diabetes 1986;35:416-20.

22 Taylor CM, Kissun RD, Schor AM, et al. Endothelial cell-stimulating angiogenesis factor in vitreous from extraretinal neovascularisations. Invest Ophthalmol Vis Sci 1989;30:2174-8. 
23 Sivalingam A, Kenney J, Brown GC, et al. Basic fibroblast growth factor levels in the vitreous of patients with proliferative diabetic retinopathy. Arch Ophthalmol 1990;108:869-72.

24 Aiello LP, Avery RL, Arrigg PG, et al. Vascular endothelial growth factor in ocular fluid of patients with diabetic retinopathy and other retinal disorders. N Engl J Med 1994;331:1480-7.

25 Adamis AP, Miller JW, Bernal MT, et al. Increased vascular endothelial growth factor levels in the vitreous of eyes with proliferative diabetic retinopathy. Am J Ophthalmol 1994:118:445-50.

26 Khaliq A, Foreman D, Ahmed A, et al. Increased expression of placenta growth factor in proliferative diabetic retinopathy. Lab Invest 1998;78:109-16.

27 Canton A, Burgos R, Hernandez C, et al. Hepatocyte growth factor in vitreous and serum from patients with proliferative diabetic retinopathy. $\mathrm{Br} J$ Ophthalmol 2000;84:732-5.

28 Watanabe D, Suzuma K, Matsui S, et al. Erythropoietin as a retinal angiogenic factor in proliferative diabetic retinopathy. N Engl J Med 2005;353:782-92.

29 Patel JI, Hykin PG, Gregor ZJ, et al. Angiopoietin concentrations in diabetic retinopathy. Br J Ophthalmol 2005;89:480-3.

30 Kohner EM, Hamilton AM, Joplin GF, et al. Florid diabetic retinopathy and its response to treatment by photocoagulation or pituitary ablation. Diabetes 1976;25:104-10.

31 Kuiper EJ, de Smet MD, van Meurs JC, et al. Association of connective tissue growth factor with fibrosis in vitreoretinal disorders in the human eye. Arch Ophthalmol 2006;124:1457-62.

32 Thieme H, Aiello LP, Takagi $\mathrm{H}$, et al. Comparative analysis of vascular endothelial growth factor receptors on retinal and aortic vascular endothelial cells. Diabetes 1995;44:98-103.

33 Aiello LP, Northrup JM, Keyt BA, et al. Hypoxic regulation of vascular endothelial growth factor in retinal cells. Arch Ophthalmol 1995; 113:1538-44.

34 Shima D, Adamis AP, Ferrara N, et al. Hypoxic induction of endothelial cell growth factors in retinal cells: identification and characterisation of vascular endothelial growth factor (VEGF) as the sole mitogen. Mol Med 1995;2:182-93

35 Tolentino MJ, McLeod DS, Taomoto M, et al. Pathologic features of vascular endothelial growth factor-induced retinopathy in the nonhuman primate. Am J Ophthalmol 2002;133:373-85.

36 Aiello LP, Pierce EA, Foley ED, et al. Suppression of retinal neovascularisation in vivo by inhibition of vascular endothelial growth factor (VEGF) using soluble VEGF-receptor chimeric proteins. Proc Natl Acad Sci USA 1995:92:10457-61.

37 Amin RH, Frank RN, Kennedy A, et al. Vascular endothelial growth factor is present in glial cells of the retina and optic nerve of human subjects with nonproliferative diabetic retinopathy. Invest Ophthalmol Vis Sci 1997:38:36-47

38 Boulton $M$, Foreman D, Williams $G$, et al. VEGF localisation in diabetic retinopathy. Br J Ophthalmol 1998;82:561-8.

39 Smith G, McLeod D, Foreman D, et al. Immunolocalisation of the VEGF receptors FLT-1, KDR, and FLT-4 in diabetic retinopathy. Br J Ophthalmol 1999:83:486-94.

40 Eriksson U, Alitalo K. VEGF receptor 1 stimulates stem-cell recruitment and new hope for angiogenesis therapies. Nat Med 2002;8:775-7.

41 Gerhardt H, Golding M, Fruttiger M, et al. VEGF guides angiogenic sprouting utilizing endothelial tip cell filopodia. J Cell Biol 2003;161:1163-77.

42 Ashton N. Injection of the retinal vascular system in the enucleated eye in diabetic retinopathy. Br J Ophthalmol 1950;34:38-41.

43 Ashton N. Arteriolar involvement in diabetic retinopathy. Br J Ophthalmol 1953;37:282-92.

44 Bresnick GH, Engerman R, Davis MD, et al. Patterns of ischaemia in diabetic retinopathy. Trans Am Acad Ophthalmol Otolaryngol 1976;81:694-709.

45 Shimizu K, Kobayashi Y, Muraoka K. Mid-peripheral fundus involvement in diabetic retinopathy. Ophthalmology 1981;88:601-12.

46 Cogan DG, Kuwabara T. Capillary shunts in the pathogenesis of diabetic retinopathy. Diabetes 1963;12:293-300.

47 Lee PF. Clinical and histological findings in diabetic retinopathy. Am J Ophthalmol 1968;65:688-95.

48 Tanaka T, Muraoka K, Tokui K. Retinal arteriovenous shunt at the arteriovenous crossing. Ophthalmol 1998;105:1251-8.

49 Grunwald JE, Brucker AJ, Grunwald SE, et al. Retinal haemodynamics in proliferative diabetic retinopathy; a laser Doppler velocimetry study. Invest Ophthalmol Vis Sci 1993;34:66-71.

50 Barouch FC, Miyamoto K, Allport JR, et al. Integrin-mediated neutrophil adhesion and retinal leukostasis in diabetes. Invest Ophthalmol Vis Sci 2000;41:1153-8.

51 Ashton N. Retinal vascularization in health and disease. Am J Ophthalmol 1957;44:7-17

52 Archer DB. Neovascularisation of the retina (Treacher Collins Prize Essay 1976). Trans Ophthalmol Soc UK 1976;96:471-93.

53 Boulton ME, McLeod D, Garner A. Vasoproliferative retinopathies: clinical, morphogenetic and modulatory aspects. Eye, 1988;2, S124-39.

54 Hersh PS, Green WR, Thomas JV. Tractional venous loops in diabetic retinopathy. Am J Ophthalmol 1981;92:661-71.

55 Kohner EM, McLeod D, Marshall J. Diabetic eye disease. In: Keen H, Jarrett J, eds, Complications of diabetes.London:Edward Arnold, 1982

56 Wise GN. Factors influencing retinal new vessel formation. Am J Ophthalmol 1961:52:637-50.

57 Michels RG. Vitreous surgery. London: CV Mosby, 1981, 174, 222

58 Gerhardinger C, Brown LF, Roy S, et al. Expression of vascular endothelia growth factor in the human retina and in non-proliferative diabetic retinopathy. Am J Pathol 1998;152:1453-62.
59 Pe'er J, Folberg R, Itin A, et al. Upregulated expression of vascular endothelial growth factor in proliferative diabetic retinopathy. $\mathrm{Br} J$ Ophthalmol 1996;80:241-5

60 Astrup J, Siesjo BK, Symon L. Thresholds in cerebral ischaemia-the ischaemic penumbra. Stroke 1982;12:723-5.

61 Kidwell CS, Alger JR, Saver JL. Evolving paradigms in neuroimaging of the ischemic penumbra. Stroke 2004;35:2662-5.

62 Issa R, Krupinski J, Bujny T, et al. Vascular endothelial growth factor and its receptor, KDR, in human brain tissue after ischemic stroke. Lab Invest 1999;79:417-25.

63 Slevin M, Krupinski J, Slowik A, et al. Activation of MAP kinase (ERK-1/ERK-2), tyrosine kinase and VEGF in the human brain following acute ischaemic stroke. Neuroreport 2000;11:2759-64.

64 Marti HJ, Bernaudin M, Bellail A, et al. Hypoxia-induced vascular endothelial growth factor expression precedes neovascularization after cerebral ischemia. Am J Pathol 2000;156:965-76.

65 Zhang ZG, Zhang L, Tsang W, et al. Correlation of VEGF and angiopoietin expression with disruption of blood-brain barrier and angiogenesis after focal cerebral ischemia. J Cereb Blood Flow Metab 2002;22:379-92.

66 Ashton N. Studies of the retinal capillaries in relation to diabetic and other retinopathies. Br J Ophthalmol 1963;47:521-38.

67 Komoto G. The pathological anatomy of the retina and choroid after complete and partial removal of their respective blood supplies. Trans Ophthalmol Soc UK 1915:35:295-308

68 Hayreh SS, Weingeist TA. Experimental occlusion of the central artery of the retina. IV: retinal tolerance time to acute ischaemia, $\mathrm{Br} J$ Ophthalmol 1980;64:818-25.

69 Hayreh SS, Zimmerman MB. Central retinal artery occlusion: visual outcome. Am J Ophthalmol 2005;140:376-91.

70 Oii EO, McLeod D. Partial central retinal artery occlusion. Trans Ophthalmol Soc UK 1978;98:156-9.

71 McLeod D, Oii EO, Kohner EM, et al. Fundus signs in temporal arteritis. Br J Ophthalmol 1978:62:591-4

72 McLeod D. Why cotton-wool spots should not be regarded as retinal nerve fibre layer infarcts. Br J Ophthalmol 2005;89:229-37.

73 Neupert JR, Brubaker RF, Kearns TP, et al. Rapid resolution of venous stasis retinopathy after carotid endarterectomy. Am J Ophthalmol 1976:81:600-2.

74 Muraoka K, Shimizu K. Intraretinal neovascularization in diabetic retinopathy. Ophthalmology 1984;91:1440-6.

75 Nork TM, Wallow IH, Sramek SJ, et al. Muller's cell involvement in proliferative diabetic retinopathy. Arch Ophthalmol 1987;105:1424-9.

76 Bek T. Transretinal histopathological changes in capillary-free areas of diabetic retinopathy. Acta Ophthalmol (Copenh), 1994;72:409-415

77 Bek T. Localised scotomata and types of vascular occlusion in diabetic retinopathy. Acta Ophthalmol (Copenh), 1991;69:11-18.

78 Stitt AW, Gardiner TA, Archer DB. Retinal and choroidal responses to panretinal photocoagulation: an ultrastructural perspective. Graefes Arch Clin Exp Ophthalmol 1995;233:699-705.

79 Stefansson E. Ocular oxygenation and the treatment of diabetic retinopathy Surv Ophthalmol 2006:51:364-80.

80 Blankenship GW. A clinical comparison of central and peripheral argon laser panretinal photocoagulation for proliferative diabetic retinopathy Ophthalmology 1988;95:170-7.

81 McLeod D. Microsurgical management of neovascularisation secondary to posterior segment ischaemia. Eye 1991;5:252-9.

82 Taylor E, Dobree JH. Proliferative diabetic retinopathy: site and size of initial lesions. Br J Ophthalmol 1970;54:11-18.

83 Verdaguer J, le Clercq N, Holuigue J, et al. Nonproliferative diabetic retinopathy with significant capillary nonperfusion. Graefes Arch Clin Exp Ophthalmol 1987;225:157-9.

84 Kurz H, Burri PH, Djonov VG. Angiogenesis and vascular remodeling by intussusception: from form to function. News Physiol Sci 2003;18:65-70.

85 Garcia-Cardena G, Comander J, Anderson KR, et al. Biomechanical activation of vascular endothelium as a determinant of its functional phenotype. Proc Nat Acad Sci USA 2001;98:4478-85.

86 Bek T. A clinicopathological study of venous loops and reduplications in diabetic retinopathy. Acta Ophthalmol Scand 2002;80:69-75.

87 Davis MD. Vitreous contraction in proliferative diabetic retinopathy. Arch Ophthalmol 1965;74:741-51.

88 Tolentino FI, Lee PF, Schepens CL. Biomicroscopic study of vitreous cavity in diabetic retinopathy. Arch Ophthalmol 1966;75:238-46.

89 Faulborn J, Bouald S. Microproliferations in proliferative diabetic retinopathy and their relationship to the vitreous: corresponding light and electron microscopic studies. Graefes Arch Clin Exp Ophthalmol 1985;223:130-8.

90 Hamilton CW, Chandler D, Klintworth GK, et al. A transmission and scanning electron microscopic study of surgically excised preretinal membrane proliferations in diabetes mellitus. Am J Ophthalmol 1982;94:473-88.

91 Dawson DW, Volpert OV, Gillis P, et al. Pigment epithelium-derived growth factor: a potent inhibitor of angiogenesis. Science 1999;285:245-8.

92 Cai J, Jiang WG, Grant MB, et al. Pigment epithelium-derived factor inhibits angiogenesis via regulated intracellular proteolysis of vascular endothelial growth factor receptor 1. J Biol Chem 2006;281:3604-13.

93 Reardon AJ, Le Goff M, Briggs MD, et al. Identification in vitreous and molecular cloning of opticin, a novel member of the family of leucine-rich repeat proteins of the extracellular matrix. J Biol Chem 2000;275:2123-9.

94 Ramesh S, Bonshek RE, Bishop PN. Immunolocalisation of opticin in the human eye. Br J Ophthalmol 2004;88:697-702.

95 Foos RY. Vitreoretinal juncture-simple epiretinal membranes. Graefes Arch Clin Exp Ophthalmol 1974;189:231-50. 
96 Charles S. Vitreous microsurgery. Baltimore: Williams and Wilkins, 1981.

97 McLeod D, Hiscott PS, Grierson I. Age-related cellular proliferation at the vitreoretinal juncture. Eye 1987;1:263-81.

98 Duke Elder S, Dobree JH. System of ophthalmology. London: Henry Kimpton, 1967:422-48.

99 Lincoff H, Serag Y, Chang S, et al. Tractional elevations of the retina in patients with diabetes. Am J Ophthalmol 1992;113:235-42.

100 Machemer R. Pathogenesis of proliferative neovascular retinopathies and the role of vitrectomy. A hypothesis. Int Ophthalmol 1978;1:1-3.

101 Akiba J, Arzabe CW, Trempe CL. Posterior vitreous detachment and neovascularization in diabetic retinopathy. Ophthalmology 1990;97:889-91.

102 Casaroli Marano RP, Preissner KT, Vilaro S. Fibronectin, laminin, vitronectin and their receptors at newly-formed capillaries in proliferative diabetic retinopathy. Exp Eye Res 1995;60:5-17.

103 Luna J, Tobe T, Mousa SA, et al. Antagonists of integrin alpha $v$ beta 3 inhibit retinal neovascularization in a murine model. Lab lnvest 1996:75:563-73.

104 Friedlander $M$, Theesfeld CL, Sugita $M$, et al. Involvement of integrins alpha $v$ beta 3 and alpha v beta 5 in ocular neovascular diseases. Proc Natl Acad Sci USA 1996;93:9764-9.

105 Soldi R, Mitola S, Strasly M, et al. Role of alphavbeta3 integrin in the activation of vascular endothelial growth factor receptor-2. EMBO J 1999;18:882-92.

106 McLeod D. Closed intraocular microsurgery for advanced diabetic eye disease. In: Kanski JJ, Morse PH, eds. Disorders of the vitreous, retina and choroid. London: Butterwoths, 1983.

107 Wong HC, Sehmi KS, McLeod D. Abortive neovascular outgrowths discovered during vitrectomy for diabetic vitreous haemorrhage. Graefes Arch Clin Exp Ophthalmol 1989;227:237-40.

108 Hiscott P, Cooling RJ, Rosen P, et al. The pathology of abortive neovascular outgrowths from the retina. Graefes Arch Clin Exp Ophthalmol 1992;230:531-6.

109 Finkelstein D, Patz A, Fine SL, et al. Abortive foveal retinal neovascularisation in diabetic retinopathy. Retina 1981;1:62-66.

110 McLeod D, James CR. Viscodelamination at the vitreoretinal juncture in severe diabetic eye disease. Br J Ophthalmol 1988;72:413-19.

111 Asaria RHY, Kon CH, Bunce C, et al. Silicone oil concentrates fibrogenic growth factors in the retro-oil fluid. Br J Ophthalmol 2004;88:1439-42.
112 Wang J, Mcleod D, Henson DB et al. Age-dependent changes in the basal retinovitreous adhesion. Invest Ophthalmol Vis Sci 2003;44:1793-800.

113 Kuwabara T, Cogan DG. Studies of retinal vascular patterns I: normal architecture. Arch Ophthalmol 1960;64:904-11.

114 Lewis H, Abrams GW, Foos RY. Clinicopathological findings in anterior hyaloidal fibrovascular proliferation after diabetic vitrectomy. Am J Ophthalmol 1987; 104:614-18.

115 Terasaki H, Miyake Y, Mori M, et al. Fluorescein angiography of extreme peripheral retina and rubeosis iridis in proliferative diabetic retinopathy. Retina 1999:19:302-8.

116 Stefansson E, Novack RL, Hatchell DL. Vitrectomy prevents retinal hypoxia in branch retinal vein occlusion. Invest Ophthalmol Vis Sci 1990;31:284-9.

117 McLeod D, Marshall J, Kohner EM, et al. The role of axoplasmic transport in the pathogenesis of retinal cotton-wool spots. Br J Ophthalmol 1977:61:177-91.

118 Holekamp NM, Shui YB, Beebe D. Lower intraocular oxygen tension in diabetic patients: possible contribution to decreased incidence of nuclear sclerotic cataract. Am J Ophthalmol 2006;141:1027-32.

119 Itakura H, Kishi S, Kotajima N, et al. Persistent secretion of vascular endothelial growth factor into the vitreous cavity in proliferative diabetic retinopathy after vitrectomy. Ophthalmology 2004;111:1880-4.

120 Barry PJ, Hiscott PS, Grierson I, et al. Reparative epiretinal fibrosis after diabetic vitrectomy. Trans Ophthalmol Soc UK 1985; 104:285-96.

121 Foos RY, Roth AM. Surface structure of the optic nerve head 2. Vitreopapillary attachments and posterior vitreous detachment. Am J Ophthalmol 1073;76:662-71.

122 Foos RY, Kreiger $A E$, Forsythe $A B$, et al. Posterior vitreous detachment in diabetic subjects. Ophthalmol 1980;87:122-8.

123 Henkind P. Ocular neovascularisation. (The Krill Memorial Lecture). Am J Ophthalmol 1978;85:287-301.

124 Asdourian GK, Goldberg MF, Busse B. Optic disc neovascularization of uveal (choroidal or posterior ciliary) origin. Arch Ophthalmol 1977;95:998-1003.

125 Jacobs NA, Steele CA, Mills KB. Origin of disc new vessels assessed by videofluorography. Br J Ophthalmol 1988;72:394-8.

126 McLeod D, Restori M. Ultrasonic examination in severe diabetic eye disease. Br J Ophthalmol 1979;63:533-8.

127 Pendergast SD, Martin DF, Proia AD, et al. Removal of optic disc stalks during diabetic vitrectomy. Retina 1995;15:25-8. 
process. In addition, impression cytology can be used to monitor recurrences in patients with previously treated OSSN in the outpatient setting.

Although impression cytology only allows sampling of the superficial cell layers, ${ }^{1}$ the sensitivity of this technique has been documented at $70 \%$ when the lesion is found to be invasive by histology. ${ }^{2}$ Consequently, some invasive lesions may still be missed. We anticipate that there are likely to be further improvements to the technique of impression cytology to make it more logistically simple and less time-consuming, with perhaps an increase in sensitivity. In the meantime, we agree that it is a useful, often underused, complementary investigation in the management of OSSN.

\section{Anu Mathew, Thomas Stumpf, Charles McGhee}

Faculty of Medical and Health Sciences, University of Auckland, Auckland, New Zealand

Correspondence to: Prof Charles McGhee, Faculty of Medical and Health Sciences, University of Auckland, Private Bag 92019, Auckland 2001, New Zealand; c.mcghee@ auckland.ac.nz

Competing interests: None declared.

Accepted 8 February 2007

\section{REFERENCES}

1. Singh $\mathbf{R}$, Joseph A, Umapathy $T$, et al. Impression cytology of the ocular surface. Br J Ophthalmol 2005;89:1655-9.

2. Nolan GR, Hirst LW, Bancroft BJ. The cytomorphology of ocular surface squamous neoplasia by using impression cytology. Cancer 2001;93:60-7.

3. Lee GA, Hirst LW. Retrospective study of ocular surface squamous neoplasia. Aust N Z J Ophthalmol 1997:25:269-76.

4. McKelvie PA, Daniell M, McNab A, et al. Squamous cell carcinoma of the conjunctiva: a series of 26 cases. Br J Ophthalmol 2002;86:168-73.

5. Tole DM, McKelvie PA, Daniell M. Reliability of impression cytology for the diagnosis of ocular surface squamous neoplasia employing the Biopore membrane. Br J Ophthalmol 2001;85:154-8.

\section{Corrections}

doi:10.1136/bjo.2006.109199corr1

D McLeod. A chronic grey matter penumbra, lateral microvascular intussusception and venous peduncular avulsion underlie diabetic vitreous haemorrhage $(\mathrm{Br} J$ Ophthalmol 2007;91:677-89). On page 679 (left column, line 22) the sentence should read: "Eventually, the VEGF/VEGFR2 system is massively expressed within and immediately surrounding those veins giving rise to the new vessels as well as, and in continuity with, the preretinal neovasculature itself."

In the credit for the December 2007 cover "The Royal College of Ophthalmologists" was incorrectly referenced as "The Royal College of Ophthalmology". In addition the following information should have been published about the cover image:

The double wheel Phoropter was made by Davidson \& Co of Great Portland Street, London in about 1902. It is made of a wood surround which holds in the lenses the whole mounted on a brass stand. It was designed to facilitate the easy and quick introduction of a range of lenses for retinoscopy. Similar models had a chin rest for the patient and a reading chart suspended from the front of the instrument stand. The firm of Davidson made a range of testing room equipment including a perimeter, a monocular microscope of $30 \times$ magnification and a Worth-Black amblyoscope.

Courtesy of Mr Richard Keeler, Curator, Museum of the Royal College of Ophthalmologists.

We apologise for these errors.

\section{Notices}

\section{Second Sight}

Second Sight would like to hear from experienced Indian eye surgeons returning to India after training/working in the UK. Second Sight is a London based charity dedicated to the elimination of cataract blindness in India. Further details: Dr Lucy Mathen, lucymathen@ yahoo.com.

\section{Inaugural Asia Cornea Society Scientific Meeting}

13-14 March 2008, Shangri La's Rasa Sentosa Resort, Singapore.

Further details: Fax +65 6227 7291; Email: acs@snec.co.sg.

\section{Singapore National Eye Centre - 18th Anniversary International Meeting}

14-17 March 2008, Suntec City Convention Centre, Singapore.

Further details: Tel: +65 6322 8374; Fax +65 6227 7290; Email: meet@snec.com.sg.

\section{World Ophthalmology Congress (WOC) 2008}

28 June-2 July 2008

Abstract submission deadline: 15 Dec 2007.

Early bird registration: 31 Jan 2008

Further details: Email: info@woc2008hongkong. org; Website: www.woc2008hongkong.org

\section{International Agency for the Prevention of} Blindness (IAPB) 8th General Assembly

28 July-2 August 2008, Centro de Convenções Rebouças, Sao Paulo, Brazil.

Further details: Email: agency@lvpei.org.

Neuro-Ophthalmology and Strabismus - 2008 European Professors in Ophthalmology (EUPO) Residents' Course

5-6 September 2008, Geneva, Switzerland. This course organised by Professor Avinoam B Safran will provide an overview and an update on recent advances in neuro-ophthalmology and strabismus.

Further details: Website: http://eupo.eu. 